\title{
On the origin of the seasonal and interannual T-S variability of the inflow through the Strait of Gibraltar
}

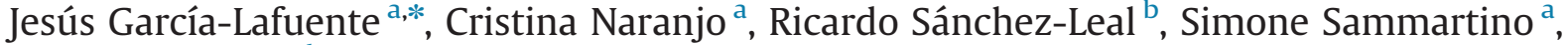 \\ Maria J. Bellanco $^{b}$, Jose C. Sánchez-Garrido ${ }^{\text {a }}$, Javier Soto-Navarro ${ }^{c}$ \\ a Grupo de Oceanografía Física, Universidad de Málaga-CEIMAR, Málaga, Spain \\ ${ }^{\mathrm{b}}$ Laboratorio Oceanográfico de Cádiz, Instituto Español de Oceanografia, Palma, Spain \\ ' Área del Medio Físico, Puertos del Estado, Madrid, Spain
}

\section{A R T I C L E I N F O}

\section{Article history:}

Received 30 June 2014

Received in revised form

4 March 2015

Accepted 13 March 2015

Available online 1 April 2015

Keywords:

Gulf of Cadiz

North Atlantic subtropical gyre

Upwelling season

Surface and advective fluxes

Seasonal signal

\begin{abstract}
A B S T R A C T
Different datasets have been analyzed to identify the origin of the temperature and salinity seasonal and interannual fluctuations in the surface layer of the eastern North Atlantic Ocean, close to the Gulf of Cadiz. The analysis was motivated by the surprising short-term salinity trend recorded by a monitoring station deployed in the Atlantic layer of the Strait of Gibraltar between years 2003 and 2007, which has been described and investigated by Millot (2007. Geophys. Res. Lett. 34, L21609. doi:10.1029/ 2007GL031179.). Temperature and salinity display similar annual cycles whose maxima occur by the end of the year, the former leading the latter by one month approximately. Despite their similarities, their origin is not the same. More than $80 \%$ of the variability of the temperature seasonal cycle is accounted for by the annual cycle of surface heat flux, while advective fluxes are secondary. This is not true for salinity, which both seasonal and interannual fluctuations are shaped by the advection and the evaporative annual cycle jointly. For the advection contribution, the identified external agent is the wind stress that drives the upwelling season in the eastern mid-latitude boundary of the North Atlantic. Vertical advection of salinity associated with the Ekman pumping and horizontal advection caused by the upwelling jet and the fluctuations of the North Atlantic Subtropical Gyre are behind the local advective changes. The strengthening (weakening) of the seasonal upwelling in summer (winter) decreased (increased) the local salinity in the Gulf of Cadiz, giving rise to the observed cycle in the data recorded at Gibraltar. Short term trends in the wind-inducing upwelling off the Iberian Peninsula during the above mentioned period triggered concomitant changes of the salinity in the waters that fed the inflow and produced the short-term trend observed in the Strait of Gibraltar.
\end{abstract}

(c) 2015 Elsevier Ltd. All rights reserved.

\section{Introduction}

Since the last decade of the past century, growing evidence that the Western Mediterranean Sea is getting saltier has been accumulated. Salinity trends reported in the literature are on the order of a few thousandths per year $\left(0.003\right.$ [psu] ${ }^{1}$ year $^{-1}$ in LópezJurado et al., 2005; 0.003 [psu] year ${ }^{-1}$ in Millot et al., 2006; 0.0043 [psu] year ${ }^{-1}$ in Grignon et al., 2010; 0.0022 [psu] year $^{-1}$ at the Dyfamed station in Marty and Chiaverini, 2010; 0.0015 [psu] year $^{-1}$ in Borghini et al., 2014). The trend could be ascribed to a

\footnotetext{
* Corresponding author at: Physical Oceanography Group, Department of Applied Physics II, University of Málaga-CEIMAR, Málaga, Spain

E-mail address: glafuente@ctima.uma.es (J. García-Lafuente).

1 Strictly speaking, the correct unit for a salinity trend is year ${ }^{-1}$, as salinity does not have units. However and for the sake of clearness, we follow here the still widely used convention of "psu" or Practical Salinity Unit, although we write it between brackets to remind the reader the license we are handling.
}

raise in the net evaporation associated with the climate change (Skliris et al., 2014; Mariotti et al., 2015; Adloff et al., 2015), but it could also be anthropogenically-induced due to the dam of large rivers, as argued in Rohling and Bryden (1992) or Skliris et al. (2007), or driven by an increase of the salinity of the Atlantic inflow through the Strait of Gibraltar, as mentioned in Schroeder et al. (2010), or a combination of all them.

From year 2003 to the end of 2008, the Atlantic inflow was monitored at the Strait by a station located over the Moroccan continental shelf close to the sill of Camarinal (inset in Fig. 1), which was part of the Hydro-Changes monitoring network sponsored by the Commission Internationale pour l'Exploration Scientifique de la Méditerranée (Mediterranean Science Commission, CIESM). The station, denoted CAM80 throughout this paper, collected hydrological observations at $80 \mathrm{~m}$ depth. Millot (2007; Mill07 hereinafter) analyzed the time subseries spanning from January 2003 to March 2007 and showed an indisputable seasonal signal accompanied by a short-term, four-year trend of $\sim 0.05$ 

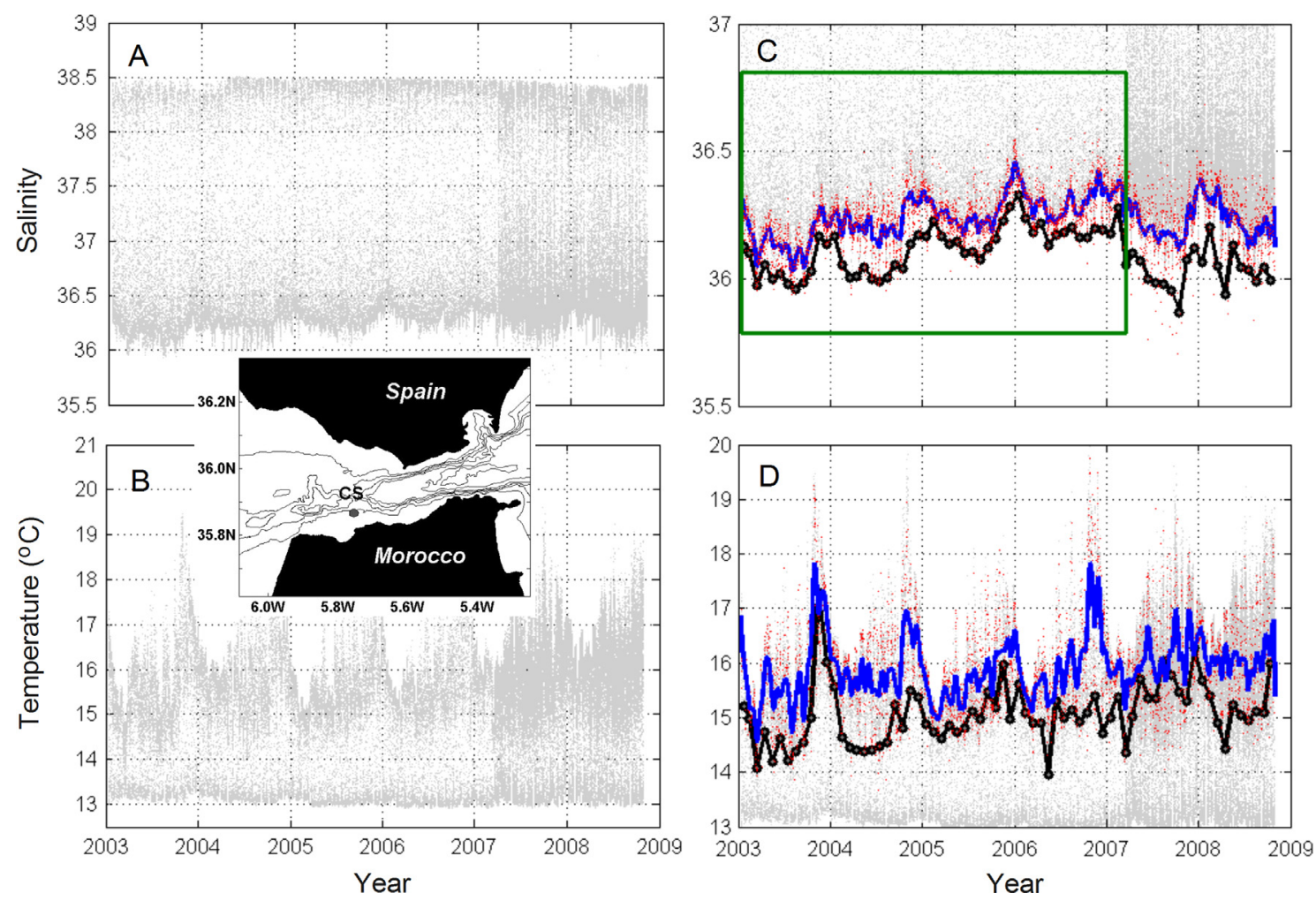

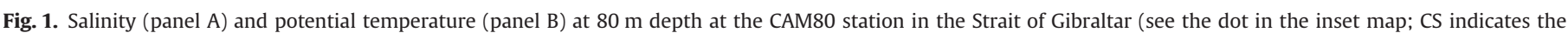

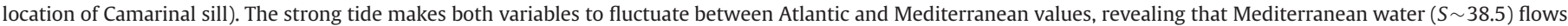

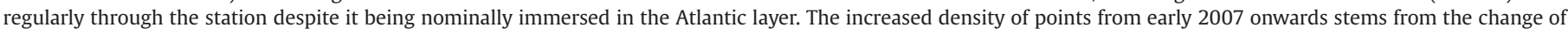

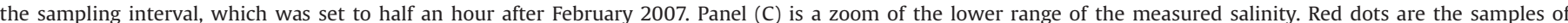

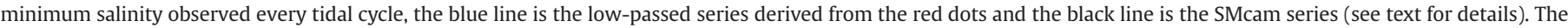

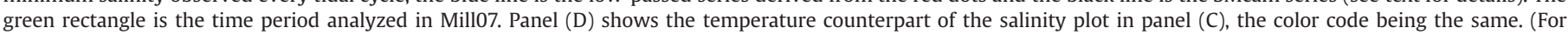
interpretation of the references to color in this figure legend, the reader is referred to the web version of this article.)

[psu] year ${ }^{-1}$ of the salinity of the Atlantic water that was flowing toward the Mediterranean Sea at the depth of the station (Fig. 3 of Mill07, see also Fig. 1C). This short-term trend is more than one order magnitude greater than the salinity trend of the Mediterranean waters reported in the literature and, therefore, it could explain it. Although it was the manifestation of the interannual variability rather than a maintained trend in time (Fig. 1C), the extra amount of salt transported by the Atlantic jet during this period (or during other similar periods) should have perceptible effects on the thermohaline circulation of the Mediterranean Sea the following years, even if the trend had not affected the whole layer of the Atlantic inflow.

The present study is motivated by the variability presented in Mill07. Our analysis is not concerned with the fate of the salinity anomaly observed at CAM80, but rather the potential origin, which must be searched for in the Gulf of Cadiz (GoC hereinafter) and the eastern North Atlantic, the source of the Atlantic inflow. There are studies addressing the variability in this area (GarcíaLafuente et al., 2004; Sánchez-Leal et al., 2007; Calafat et al., 2012; Gómez-Enri et al., 2012), although they focus mainly on the sea level and pay little attention to the changes of the hydrological properties of the upper ocean waters. Soto Navarro et al. (2012) partially addressed the issue and detected a trend of $+0.013 \pm 0.003$ year $^{-1}$ in the NACW, after analyzing a large set of ARGO profiles from years 2002 to 2010 in the mid-latitude Northeast Atlantic ocean. Despite being greater than those in the Western Mediterranean Sea, the trend is still four times less than the $\sim 0.05$ [psu] year $^{-1}$ reported in Mill07 at CAM80.

The logical assumption on which this study relies is that the same external agents that drive the seasonal signal will drive the interannual variability, the latter being merely caused by small departures of the external forces from their mean seasonal patterns. Therefore, we explore first the seasonal signal, then the short-term trend (interannual variability) in the GoC area. Concerning the seasonal signal, salinity and temperature behave in different ways. While the solar annual cycle is the main driver of the temperature seasonal cycle in the upper layer ocean at the mid-latitudes, there is no evidence for a salinity cycle driven by the net evaporation. Changes of the circulation pattern would also influence the salinity in the GoC and, hence, in the CAM80 observations. At basin scale, the North Atlantic subtropical gyre and associated surrounding currents represent the basic circulation pattern of the mid latitude eastern North Atlantic Ocean (see the sketch in Fig. 2). The Canary Current is the natural southflowing extension of the zonal Azores Current (Stramma, 1984) that forms the eastern limb of the subtropical gyre. It is also the wide transition region between the permanent coastal upwelling region off northwest Africa and the open ocean (Barton, 1998). More to the north it is the Portugal Current system, of which the upwelling region off Iberia forms part (Pérez et al., 2001; Martins et al., 2002). The GoC breaks the continuity of the coastline and separates the upwelling region into two parts with apparently no direct link of flow between them.

The basin-scale pattern undergoes wind-driven seasonal fluctuations triggered by the annual migration of the Azores highpressure system (Eden and Willebrand, 2000), which migrates meridionally between $27^{\circ} \mathrm{N}$ in March and $33^{\circ} \mathrm{N}$ in August, weakening significantly in autumn and winter (Coelho et al., 2002). Stramma and Siedler (1988) investigated the seasonal changes of the North Atlantic subtropical gyre from historical data and concluded that its eastern part showed a larger east-west and smaller north-south extension in summer compared with the 


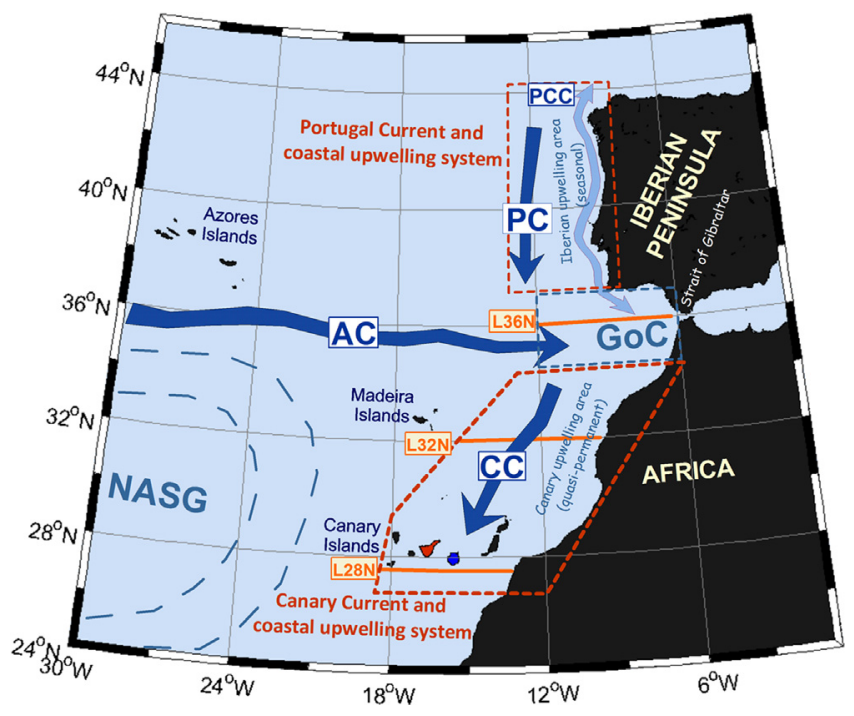

Fig. 2. Schematic of the circulation pattern in the eastern part of the North Atlantic Ocean. The relevant features for this study along with the main current systems are indicated: AC corresponds to the Azores Current, PC to the Portugal Current and CC to the Canary Current, all them being rather permanent features of the circulation. The North Atlantic Subtropical Gyre (NASG) is insinuated at the lower left corner. The Portugal coastal current (PCC) has been sketched with a double arrow to remind its intermittency in response to the seasonal wind-stress off the Iberian Peninsula. Orange lines labelled L36N, L32N, and L28N are used to compute equatorward transports. The seasonal (Portugal) and quasi-permanent (Canary) upwelling systems, and the Gulf of Cadiz box (GoC) in between have been indicated. Tenerife and Gran Canaria islands in the Canary Archipelago are highlighted in red and blue, respectively, to identify the geographical location of the sea level data employed in the study (see more details in the text). (For interpretation of the references to color in this figure legend, the reader is referred to the web version of this article.)

winter season. They also presented seasonal meridional shifts of the center of the gyre of about $2^{\circ}$, which was more to the north in winter. Carracedo et al. (2014) indicated seasonal variations of the Azores current with maximum transport in autumn and minimum in spring. Stramma and Isemer (1988) reported seasonal fluctuations of meridional heat fluxes in the eastern North Atlantic associated with changes of the location of the North Atlantic subtropical gyre. Particularly sensitive to the migrations of the Azores high is its eastern boundary, the Canary Current and Portugal Current systems (Wooster et al., 1976), whose seasonal response has been extensively analyzed in the literature (see Cropper et al. (2014) and references herein). The northerly winds along the eastern coast associated with the more northeastward location of the Azores high in summer enhance the upwelling and the coastal equatorward flows (Wooster et al., 1976). During the winter the dominant wind stress off Iberia is northwards and tends to suppress the upwelling, giving rise to a poleward slope current (Frouin et al., 1990) that leaves a warm signature in satellite images (Haynes and Barton, 1990). It is the easternmost coastal flow of the Portugal Current system, which reverses during the upwelling season (Pérez et al., 2001). Further south, in the $\mathrm{GoC}$, similar flow reversals have been also observed during winter months, especially in January (García-Lafuente and Ruiz, 2007). A feasible explanation of this seasonal dynamics was presented in Machín et al. (2006), who developed a simple quasigeostrophic model to examine the circulation of the North Atlantic subtropical gyre focusing on the northeastern corner of the gyre. The model featured north-south displacements of the transport streamlines at the eastern boundary in response to the changing pattern of the wind stress associated with the migrations of the Azores high, and recirculating cyclonic cells that would eventually reverse the flow at the eastern boundary. The seasonal changes of the circulation in the vicinity of the GoC would be the result of the variable location of the streamlines round the year.

This work studies the seasonal variability and the interannual fluctuations of the hydrological properties in the GoC to provide an explanation to the observations collected at CAM80. The paper is organized as follows. The next section presents the datasets used in the study. Section 3 analyses the seasonal signal in the GoC and investigates the source and origin of the annual cycles of temperature and salinity in the eastern North Atlantic near to the GoC, assessing the relative importance of surface versus advective fluxes. Following our assumption that the seasonal and interannual variabilities are consequences of the same external agents, Section 4 addresses the seasonal cycle of the salinity cycle, exploring the links between the observed signal nearby the GoC and the annual fluctuations of the large-scale features such as the North Atlantic subtropical gyre and the wind field in the eastern North Atlantic. After the origin of the seasonal salinity signal is investigated, Section 5 focuses on the period of Mill07 data and the short-term trend found in the Camarinal data. Finally, Section 6 summarizes our findings and conclusions.

\section{Data and data processing}

\subsection{The datasets}

Several datasets have been used in this study. Most of them consist of gridded products available in international databases, which are completed by the observations collected at CAM80 station.

(1) Gridded temperature and salinity ARGO data produced at Scripps Institution of Oceanography following the analysis method by Roemmich and Gilson (2009), which are freely available through the Global Argo Marine Atlas (http://www.argo.ucsd. edu/Marine_Atlas.html). The dataset covers the period from January 2003 to December 2012 and the data are given as monthly means at 58 z-levels (every $10 \mathrm{~m}$ from the surface to $180 \mathrm{~m}$, every $20 \mathrm{~m}$ from $200 \mathrm{~m}$ to $460 \mathrm{~m}$, every $50 \mathrm{~m}$ from $500 \mathrm{~m}$ to $1400 \mathrm{~m}$ and every $100 \mathrm{~m}$ from $1500 \mathrm{~m}$ to the last level at $2000 \mathrm{~m}$ ) with $1^{\circ} \times 1^{\circ}$ spatial resolution

(2) Velocity, temperature and salinity ECCO (Estimating the Circulation and Climate of the Ocean) data from January 1993 to December 2013. The ECCO code is based on the Massachusetts Institute of Technology general circulation model (MITgcm; Marshall et at. 1997a,1997b), a numerical model designed for study of the atmosphere, ocean, and climate, applied to a nearglobal domain. The model resolution is $1^{\circ}$ horizontally except within the tropics where the meridional resolution gradually decreases to $0.3^{\circ}$ at $10^{\circ}$ of the Equator. There are 46 vertical levels with $10 \mathrm{~m}$ resolution in the 150 first meters. The model is forced by the National Center for Atmospheric Research reanalysis products, with time means replaced by those of COADS. Temperature and salinity are further relaxed towards observed surface values. The output fields are presented as 10-day averages.

(3) Wind products and heat and freshwater fluxes provided by the NCEP reanalysis project. The data are available at http://www. cpc.ncep.noaa.gov/products/wesley/reanalysis.html), the web page of the Climate Prediction Center (CPC). The downloaded data are daily values spanning the period 1992-2013 (both years included) and covering the North Atlantic ocean from the equator to $65^{\circ} \mathrm{N}$ on a square $2.5^{\circ}$ (winds) and $\sim 1.9^{\circ}$ (heat fluxes) global grid using a state-of-the-art analysis/forecast system to perform data assimilation using data from 1948 to the present (Kalnay et al., 1996).

(4) North Atlantic Oscillation (NAO) and Eastern Atlantic (EA) climatic indices provided by the CPC (http://www.cpc.ncep.noaa. 
gov/data/teledoc/teleindcalc.shtml). These data were used to search for correlations with the main modes of atmospheric variability.

(5) Sea level data at the ports of Gran Canaria $\left(27.85^{\circ} \mathrm{N}, 15.4^{\circ} \mathrm{W}\right.$, highlighted in blue in Fig. 2) and Tenerife $\left(28.5^{\circ} \mathrm{N}, 16.25^{\circ} \mathrm{W}\right.$, highlighted in red in Fig. 2), in the Canary Islands from the REDMAR tide-gauge network of Puertos del Estado (Spain). The data are monthly averages covering the period 1993-2013 and have been used to detect seasonal fluctuations of the Canary Current.

(6) The already mentioned data from CAM80 station located at $35.88^{\circ} \mathrm{N}, 5.72^{\circ} \mathrm{W}$ at $80 \mathrm{~m}$ depth in the Strait of Gibraltar, described in Millot (2007) and Millot and García-Lafuente (2011).

\subsection{Data processing}

Data from the first five sources have been exploited as provided by the respective data centers, with no further processing. Data from the first three databases have been employed to estimate heat and salt balances from the advection-diffusion equations applied to a control volume according to the procedure described in Appendices A-C.

Observations from CAM80 have been processed to obtain representative time series of the Atlantic water flowing into the Mediterranean Sea. The station is inside the Atlantic layer since the interface separating Atlantic and Mediterranean waters lays below $100 \mathrm{~m}$ depth in the vicinity of Camarinal sill (SánchezGarrido et al., 2011) and it is even deeper in the southern part of the Strait of Gibraltar due to the Earth's rotation (Echevarría et al. 2002). The measured salinity is thus expected to be less than 36.5 , which is an upper limit for Atlantic waters salinity in the oceanic side of the Strait. Fig. 1A, however, shows that this is not anywhere near the case. The strong tide in the Strait causes vertical oscillations of the interface large enough to flood CAM80 with salty Mediterranean water almost every tidal cycle, which makes the observations run the whole range of salinities from 36, typical of the upper North Atlantic Central Water (NACW) to 38.5 of the Mediterranean water

The fact that the NACW exhibits an absolute salinity minimum in the Strait of Gibraltar (see Fig. 3) has been exploited to identify the Atlantic water in the CAM80 records. By selecting the freshest sample observed every tidal cycle a new, nearly tide-free time subseries is worked out (Fig. 1C). The ten lowest salinity samples of this semidiurnal selection recorded each month have been averaged to build a monthly time series (SMcam series hereinafter), which is shown in black in Fig. 1C. This series gives suitable information on the low frequency variability of the Atlantic water that would be flowing into the Mediterranean Sea in the absence of tides. In particular it shows the clear seasonal signal superposed to the longer-term interannual fluctuation reported in Mill07. Despite the unavoidable contamination of the Atlantic water at CAM80 by tidal mixing, Fig. $1 \mathrm{C}$ shows that the seasonal and interannual signals of the NACW in the GoC are still well recognizable when this water flows through CAM80. The temperature corresponding to the salinity points in SMcam (TMcam series hereinafter) is plotted in black in Fig. 1D.

\section{The seasonal cycle in upper layer of the Gulf of Cadiz}

\subsection{The observed temperature and salinity seasonal signals}

A subset of ARGO data in the area $35-37^{\circ} \mathrm{N}, 6-12^{\circ} \mathrm{W}$ (GoC box hereinafter, see Fig. 3), which will be denoted by ARGOGoC data, has been used to identify the depth range occupied by water with SMcam and TMcam characteristics. Fig. 3 shows that $120 \mathrm{~m}$ is a fair representative average depth, although the depth can range from 80

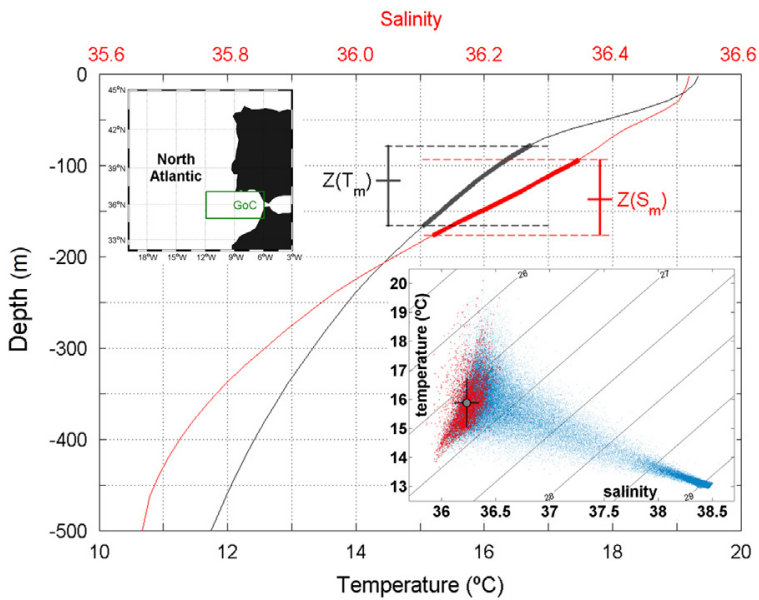

Fig. 3. Spatial and time-averaged temperature (black line, bottom axis) and salinity (red line, top axis) vertical profiles in the GoC box $\left(35-37^{\circ} \mathrm{N}, 6-12^{\circ} \mathrm{W}\right.$, see rectangle in the upper-left inset) from ARGO profilers. The averaged period is January, 2004 to December, 2012. Blue dots in the TS diagram are the whole dataset recorded at CAM80 while the red dots are the subset of minimum salinity recorded every tidal cycle, the same subset as in Fig. 1. The large grey dot and the black lines in the diagram indicate the mean and the reach of \pm 1 std of this data subset. The thick portions of the temperature and salinity vertical profiles show the depth interval in which these variables have numerical values inside the mean +1 std interval in the TS diagram. The interval is also indicated by the vertical segments, which explicitly marks the depth of the mean temperature $\left(Z\left(T_{m}\right)=-117 \mathrm{~m}\right)$ and salinity $\left(Z\left(S_{m}\right)=-137 \mathrm{~m}\right)$. Salinity shows a rather constant gradient of $0.0026 \mathrm{~m}^{-1}$ between 30 and $240 \mathrm{~m}$. (For interpretation of the references to color in this figure legend, the reader is referred to the web version of this article.)

to $170 \mathrm{~m}$. A feature worth mentioning in this figure is the linear vertical profile of salinity between 30 and $240 \mathrm{~m}$ depth, typical of the NACW, with a constant salinity gradient of $\partial S / \partial z=0.0026 \mathrm{~m}^{-1}$. Fig. 4 shows the spatially averaged salinity and temperature and their anomalies in the GoC box at several depth layers. In the surface layer $(z<50 \mathrm{~m})$ the seasonal cycle of temperature is quite sinusoidal, with $\sim 2.5{ }^{\circ} \mathrm{C}$ amplitude peaking in late summer (Fig. $4 \mathrm{C}$ and D). Salinity cycle is far less sinusoidal. The amplitude of the fluctuations of both variables damps out with depth, with a decrease more pronounced for temperature (compare columns 4 and 7 in Table 1). Fig. 4 also illustrates a shifting of the maxima toward autumn/winter with depth.

These facts are better seen in Fig. 5, which shows the results of a harmonic regression model of annual and semiannual frequencies applied to the ARGOGoC data. Temperature is clearly dominated by the annual signal, whose amplitude diminishes by more than $90 \%$ in the first $100 \mathrm{~m}$ (from $3.2{ }^{\circ} \mathrm{C}$ at the surface to $0.2{ }^{\circ} \mathrm{C}$ at $100 \mathrm{~m}$ depth, Fig. 5C) and becomes no-significantly different from zero below $130 \mathrm{~m}$. Compared with the annual signal, the semiannual contribution is negligible. Salinity amplitude also decreases fast in the first tens of meters to reach a non-significant value below $150 \mathrm{~m}$ (Fig. 5A). The ratio at $100 \mathrm{~m}$ (0.027) with respect to the surface (0.11) is much higher than for temperature, in agreement with the information in Table 1 . Salinity semiannual amplitude exceeds the annual one at depths greater than $60 \mathrm{~m}$, distorting the annual cycle below this depth (see Fig. 4B). In the uppermost $150 \mathrm{~m}$ the phases increase downwards (Fig. 5B and D), indicating a latter occurrence of the maximum with depth. At $80 \mathrm{~m}$, the salinity peaks in early January (phase slightly greater than zero) while it does by the end of October for temperature. The agreement between annual phases of ARGOGoC data and SMcam and TMcam series is remarkably good (red dots in Fig. 5B and D), although it is not that good for the amplitude of SMcam. This fact is attributed to the mixing that contaminates the salinity fluctuations of the NACW as this water flows through the Strait of Gibraltar. Although the procedure used to extract the best NACW 


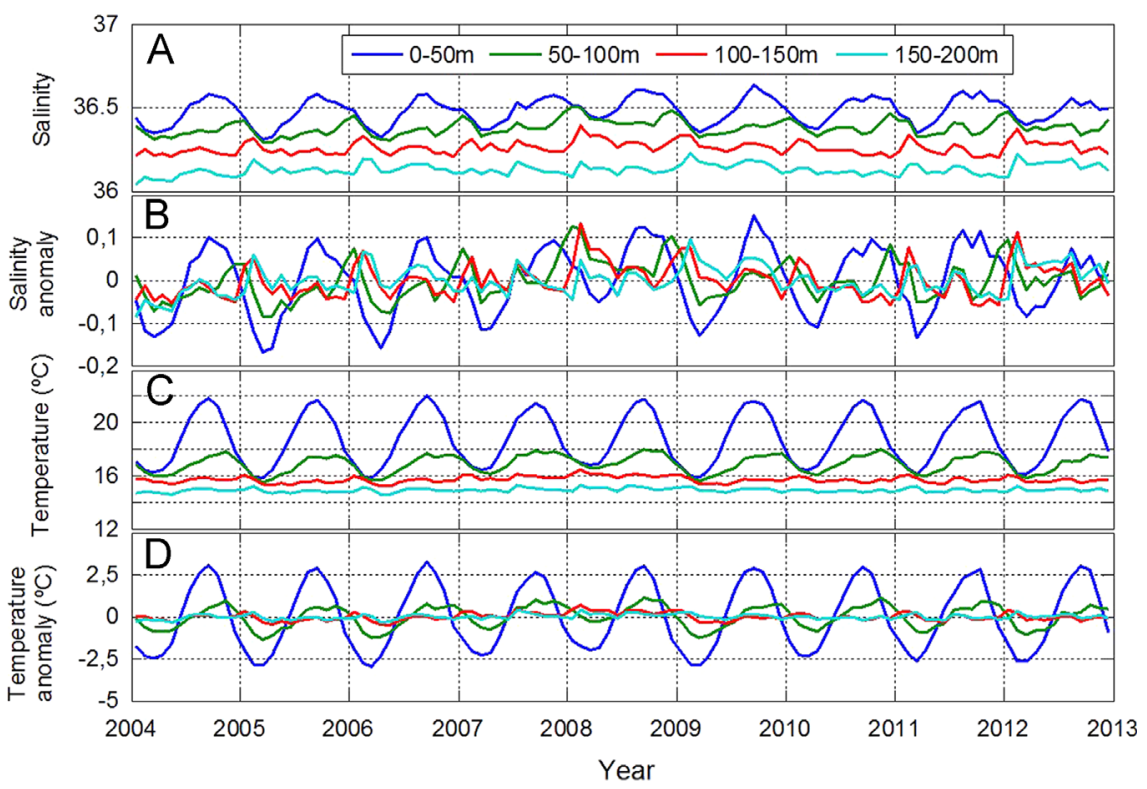

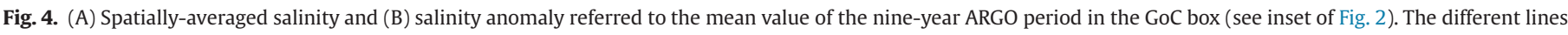
correspond to the depth layers displayed in the legend. Panels (C) and (D) show the corresponding plots for temperature.

Table 1

Spatially-averaged properties of the subsurface water in the Gulf of Cadiz (GoC box see text) at the different depth layers specified in the first column. The first block is for temperature and displays the mean, standard deviation and the standard deviation normalized by the first layer value, respectively. The second block displays the analogous information for salinity. Last column indicates the shortterm salinity trend from January 2004 to March 2007, the common period of ARGOGoC data and CAM80 observations in Mill07 study.

\begin{tabular}{llclllll}
\hline Layer $(\mathbf{m})$ & $\begin{array}{l}\boldsymbol{T}_{\text {mean }} \\
\left({ }^{\circ} \mathrm{C}\right)\end{array}$ & $\begin{array}{l}\boldsymbol{T}_{\text {std }} \\
\left({ }^{\circ} \mathrm{C}\right)\end{array}$ & $\begin{array}{l}\boldsymbol{T}_{\text {std, }} \\
\text { nor } \\
(\%)\end{array}$ & $\begin{array}{l}\boldsymbol{S}_{\text {mean }} \\
([\mathrm{psu}])\end{array}$ & $\begin{array}{l}\boldsymbol{S}_{\text {std }} \\
([\mathrm{psu}])\end{array}$ & $\begin{array}{l}\boldsymbol{S}_{\text {std, }} \\
\text { nor } \\
(\%)\end{array}$ & $\begin{array}{l}\text { Trend (Jan04- } \\
\text { Mar07) ([psu] } \\
\left.\text { year }^{-1}\right)\end{array}$ \\
\hline $0-50$ & 18.78 & 2.00 & 100 & 36.48 & 0.079 & 100 & 0.019 \\
$50-100$ & 16.90 & 0.67 & 33.6 & 36.38 & 0.045 & 57.4 & 0.012 \\
$100-150$ & 15.71 & 0.23 & 11.7 & 36.26 & 0.039 & 49.1 & 0.010 \\
$150-200$ & 14.92 & 0.15 & 7.6 & 36.13 & 0.034 & 43.4 & 0.021 \\
\hline
\end{tabular}

samples at CAM80 minimizes the effect of mixing, it does not remove its consequences entirely.

Despite some similarity, the dependence of the harmonics of temperature and salinity with depth is different. The ratio of the annual-to-semiannual amplitude in the upper $100 \mathrm{~m}$ is much higher for temperature (Fig. 5A), which has well-shaped sinusoidal form in this layer (Fig. 4C and D). The black line in Fig. 5D shows the difference of annual phase between both variables, the maximum of salinity always occurs after the maximum of temperature at all depths. The difference is $\sim 20^{\circ}$ (somewhat less than a month) in the first $50 \mathrm{~m}$ and increases to $\sim 90^{\circ}$ (three months) in the depth range of $80-130 \mathrm{~m}$. All this suggests that the origin of the annual cycle is not the same for both variables.

\subsection{The influence of surface fluxes on the temperature and salinity seasonal cycles}

The advection-diffusion equation written in its integral form (see Appendix A for details) has been used to address the influence of the surface fluxes on the annual cycles of the temperature and salinity. In a first step, the balance between the local variation and the surface flux terms in the GoC box has been investigated. A derivation of the surface flux for salinity is presented in Appendix B (Eq. (B.5)) whereas the surface flux for temperature is the well-known Eq. (A.4). The local variations have been computed from the ARGOGoC and/or ECCO datasets according to Eq. (C.2) and Eq. (C.4) of Appendix C with $h=150 \mathrm{~m}$. Below this depth, the seasonal signals are not significantly different from 0 (Fig. 4). The surface fluxes have been computed from Eq. (C.3) and Eq. (C.5) using the NCEP re-analysis data, $t_{2}$ and $t_{1}$ referring to the central day of two consecutive months.

For temperature, both terms of Eq. (C.2) fluctuate in phase with similar amplitude, suggesting a first balance between the local variation and the surface heat flux. In fact, the variance of the residue $\Delta H_{C}(t)-H_{S}(t)$ ( $t$ refers to the successive months; see Appendix $C$ for nomenclature) is only the $18 \%$ of the variance of $\Delta H_{C}(t)$, implying that the surface heat flux $H_{S}(t)$ accounts for the $82 \%$ of the seasonal variability of the heat content (or temperature signal) of the layer. A similar balance does not hold for salinity because the term $\Delta \bar{S}$ (Eq. (C.4)) shows seasonal characteristics that are not well depicted by the term $h^{-1} \bar{S}_{E}$. These results give support to the hypothesis that local variations of temperature and salinity respond to different mechanisms.

\subsection{Advective fluxes in the temperature and salinity seasonal cycles}

The advective terms in Eq. (A.3) are retained now to assess their influence on the seasonal cycles (Fig. 6). As the advective flux computation makes use of the velocity field, which is not available in the ARGOGoC dataset, the outputs of the ECCO model are used instead. Geostrophic velocity estimated from altimetry was another choice that was discarded because geostrophy precludes vertical velocity whose role in the advection cannot be neglected. Supporting the use of ECCO data for this analysis is the fact that both ECCO and ARGOGoC databases provide very similar results (see Fig. 8), which is not surprising as ECCO assimilates ARGO data and thereby provides a consistent dynamical field with it.

Fig. 6 displays the local variation and advective and surface fluxes for the temperature and salinity (see the figure caption for more details) computed directly from Eq. (A.3), which have been spatially averaged in the GoC box. In the case of temperature, Fig. $6 \mathrm{~A}$ confirms that the main balance occurs between the local variation and the heat flux across the sea surface (correlation coefficient of $r=0.96$ ). The advective flux is secondary and significantly less correlated with the heat content $(r=0.21)$. It tends to co-oscillate with it and with the surface heat flux, and appears 

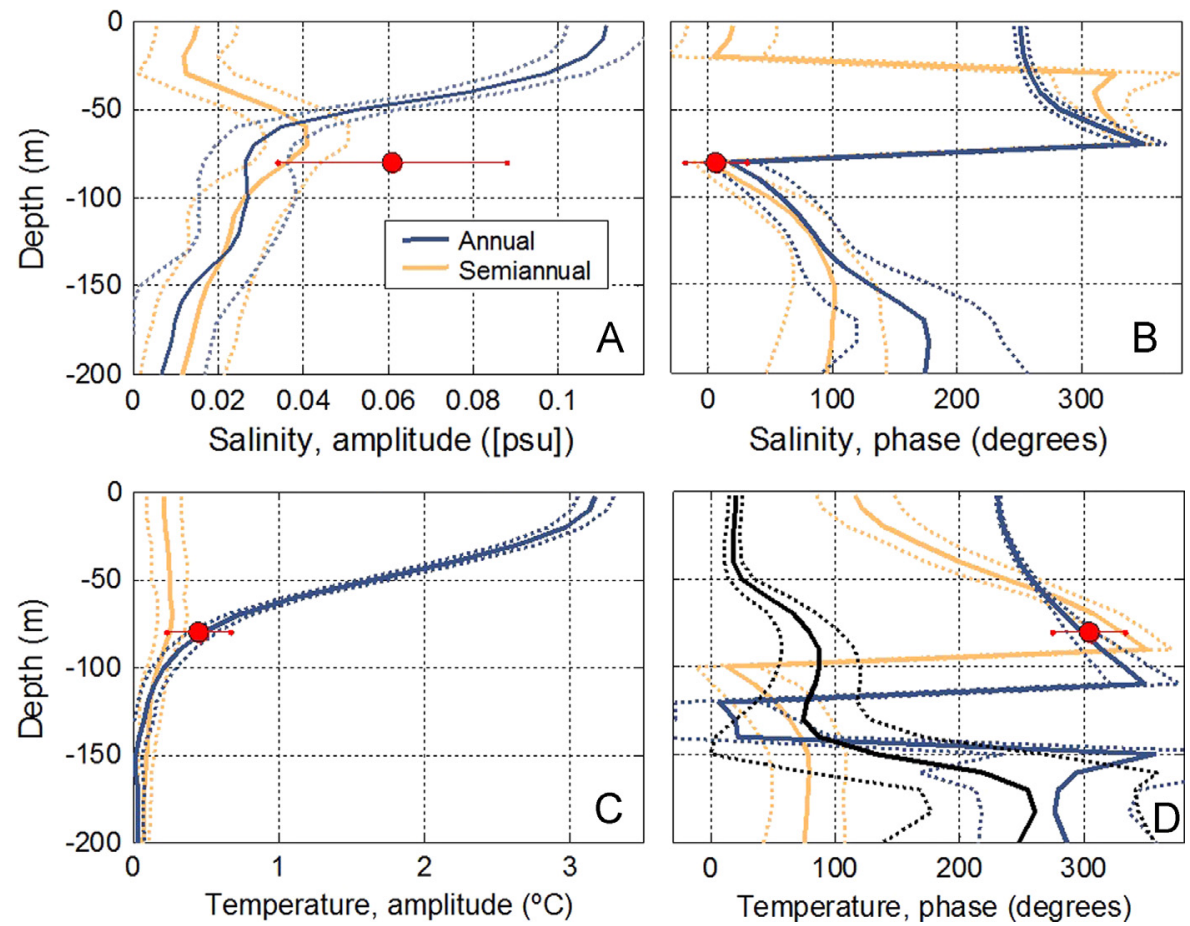

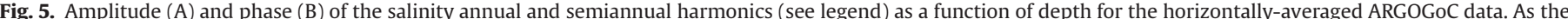

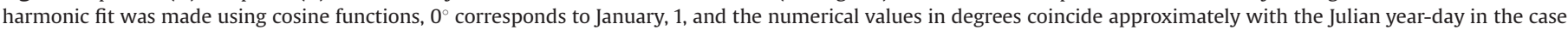

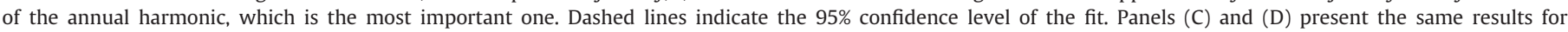

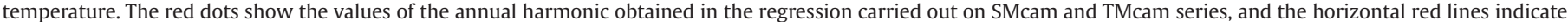

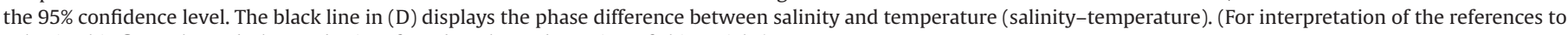
color in this figure legend, the reader is referred to the web version of this article.)
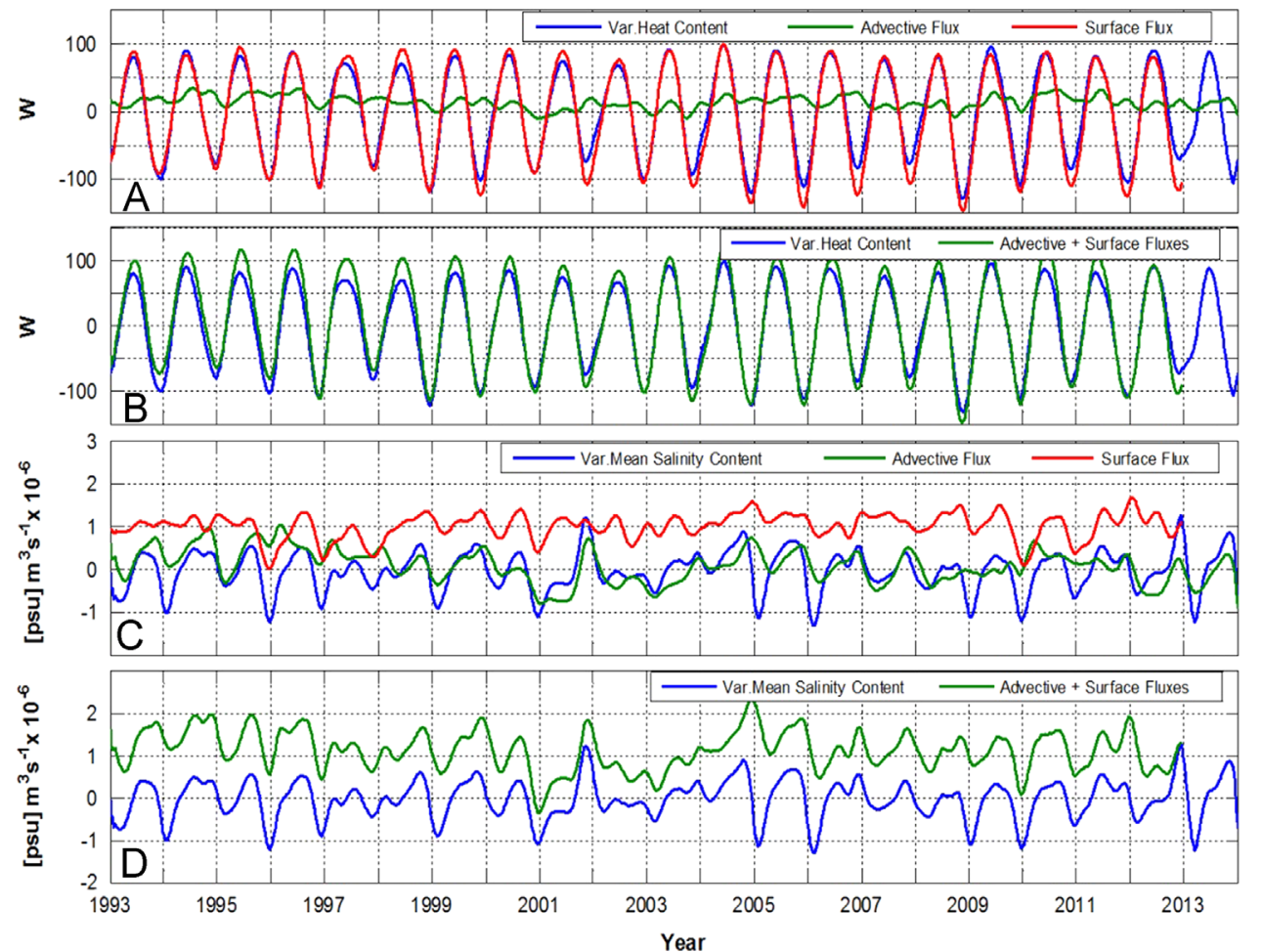

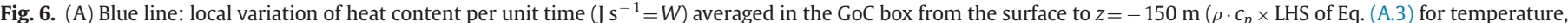

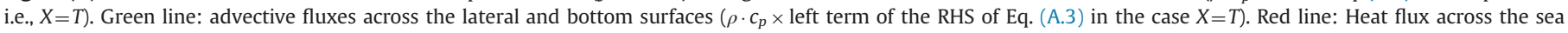

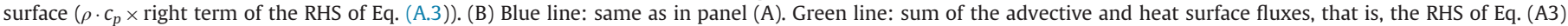

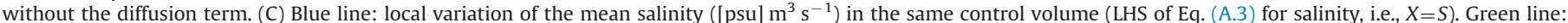

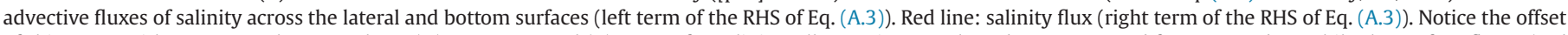

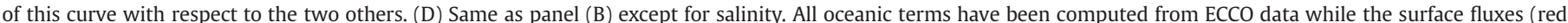

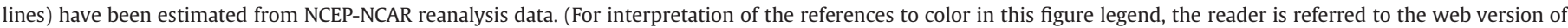
this article.) 
slightly shifted onwards. Fig. $6 \mathrm{~B}$ shows the two sides of the temperature equation (LHS, which is the same as in Fig. 6A, and the RHS, which is the sum of the two fluxes). The correlation between both terms increases very slightly $(r=0.97)$.

Fig. 6C and D display the results in the case of the salinity. The correlation between the local variations and the surface fluxes drops to $r=0.56$ while the correlation with the advective fluxes rises to a significant $r=0.49$. The conclusion drawn from Fig. $6 \mathrm{C}$ is that the primary balance is no longer achieved between the local variations and the fluxes through the sea surface because the advective fluxes cannot be neglected. When surface and advective fluxes are added, they depict a shape much like the local variation term (Fig. 6D) and the correlation growths to $r=0.71$. Both curves have an offset of $\sim 10^{-6}$ [psu] $\mathrm{m}^{3} \mathrm{~s}^{-1}$ that, judging from Fig. 6C, comes from the surface flux term. It could be possible that the term $(E-P)$ that governs the surface flux for salinity is not well determined in the GoC area.

\section{The seasonal cycle and the large-scale circulation of the eastern North Atlantic}

\subsection{The seasonal variability of the North Atlantic subtropical gyre inferred from hydrological data.}

While the annual cycle of solar radiation explains most of the temperature seasonal signal in the GoC (and elsewhere), the evaporative cycle only accounts partially for the salinity cycle, which would be linked to the seasonality of other processes related to the large-scale patterns of the North Atlantic Ocean. The rest of the paper concentrates on such processes and investigates its likely origin.

Fig. 7 displays the spatial patterns of the surface salinity and temperature as deduced from ARGO and ECCO datasets. Both maps are pointedly shown to illustrate that they reproduce almost identical large-scale spatial and temporal patterns, similitudes already exploited in the previous section. Despite these similitudes, the observations are preferably used whenever possible. Therefore, ARGO data are employed in issues related to temperature and salinity.

Fig. 7A and B show that the North Atlantic subtropical gyre leaves a visible footprint in the salinity field, which consists of closed salinity contours for $S>36.7$ approximately, while the gyre cannot be guessed from the rather zonal pattern of the surface temperature maps (Fig. 7C and D). Surface salinity is then a good proxy to follow the fluctuations of the North Atlantic subtropical gyre. For example, Fig. 7A and B highlight the $S=37.0$ contour (deep-red shaded area) and the location of this isohaline in the climatological April (yellow contour) and October (blue-gray contour) months. The location of these contours suggests that the North Atlantic subtropical gyre moves northwards and eastwards in autumn with regard to spring, which would agree with previous results by Stramma and Siedler (1988) or the more recent analysis by Carracedo et al. (2014). The seasonal behavior of the surface isotherms is useless to this aim. They are displaced meridionally by more than a thousand $\mathrm{km}$ (Fig. 7C and D) preserving their zonal pattern, a behavior clearly indicative of a temperature seasonal cycle driven by the solar radiation.

Fig. 7E shows the amplitude of the annual signal of the averaged salinity in the upper $100 \mathrm{~m}$ of the North Atlantic. Fig. $7 \mathrm{~F}$ zooms on the eastern part of the basin and labels some phase isolines to illustrate the time of the seasonal peak. Although the amplitude is close to zero over the extension of the North Atlantic subtropical gyre, there is an oblong-shaped distinguishable area stretching from approximately $25^{\circ} \mathrm{N}, 35^{\circ} \mathrm{W}$ to the GoC (Fig. 7F) where the signal is clearly non null. It seems to be caused by the seasonal fluctuations of the position and shape of the North Atlantic subtropical gyre, as suggested by the changing location of $S=37$ in the maps of Fig. 7A and B. Fig. 7G and $\mathrm{H}$ present the results for temperature. The equi-amplitude lines are zonally arranged in a pattern that resembles the mean field in Fig. 7C although the pattern is slightly distorted near the GoC (Fig. $7 \mathrm{H}$ ). The phase is $\sim 30^{\circ}$ less than for salinity (Fig. $7 \mathrm{~F}$ ), meaning that temperature peaks 30 days earlier than salinity, in agreement with the results of Section 3.1.

The annual and interannual changes of the location and extension of the North Atlantic gyre are illustrated in Fig. 8. Two proxies have been used to characterize these changes: the superficial area of $S \geq 37$ (Fig. 8A), which informs about the size of the gyre, and the latitude and longitude of the central point of this area (Fig. 8B), which indicate the changing location of the gyre. The latitude is the most regular of all the three parameters (the seasonal cycle explains nearly the $80 \%$ of its variance), suggesting a highly predictable north-south migration of the North Atlantic gyre of $\sim 2^{\circ}$, in agreement with Stramma and Siedler (1988). The harmonic fitting yields a phase of $246 \pm 5^{\circ}$, which implies a northernmost position of the gyre in the first half of September, a timing that does not agree with these authors, who indicated a northernmost position in winter. Although the east-west displacements are less sinusoidally-shaped (upper plot in Fig. 8B), they still depict a seasonal cycle of $\sim 70 \mathrm{~km}$ amplitude with its easternmost reach around the end of the year $\left(354 \pm 17^{\circ}\right)$. Only $37 \%$ of the original variance is accounted for by the annual cycle in this case, the interannual variability being more important. Notice that, while north-south fluctuations are encouragingly similar in the ECCO and ARGO datasets, they are not that good in longitude, the latter data indicating a more westwards central position. Despite this lack of agreement, the size and phase of the fluctuations are similar in both datasets. The area of the gyre (Fig. 8A) shows the poorest, though yet recognizable, seasonal signal $(\sim 20 \%$ of explained variance) with maximum extension of the gyre around the end of July.

\subsection{The large-scale wind field}

Since the North Atlantic subtropical gyre is a wind-driven feature, its seasonal fluctuations must be correlated to the seasonality of the wind field, which in turn is linked to the migrations of the Azores high. The NCEP wind field has been analyzed by means of the broadly used Empirical Orthogonal Functions technique (EOF, Preisendorfer, 1988) to characterize the wind variability during the period of study. The technique of spatial composite of data sets (Boutov et al., 2014) has been used to carry out the analysis because the wind velocity is a vector. Furthermore, the geographical area has been restricted to the eastern part of the North Atlantic, namely, to the area sketched in Fig. 2 in order to obtain a better spatial definition of the wind variability in the region of interest.

The results of the analysis is presented in Fig. 9. We only show the leading two modes (Fig. 9A and C), which account for the 75\% and 7\% of the variance of the wind field. The time coefficients of these modes show a seasonal oscillation, which is more regular in the case of the first mode (Fig. 9B), and interannual fluctuations, which are clearer for the second mode (Fig. 9D). The analysis was performed without removing the spatial mean so that the first mode is expected to depict the mean field, which is the flow along the eastern boundary of the Azores high-pressure system. To check this point, the spatially averaged wind velocity inside the box marked in purple in Fig. 9A, which comprises the upwelling systems and the GoC area indicated in Fig. 2, has been computed and the time evolution of the meridional and zonal components have been plotted in Fig. 9B and $D$, respectively. As expected, the time coefficients of mode \#1 are 

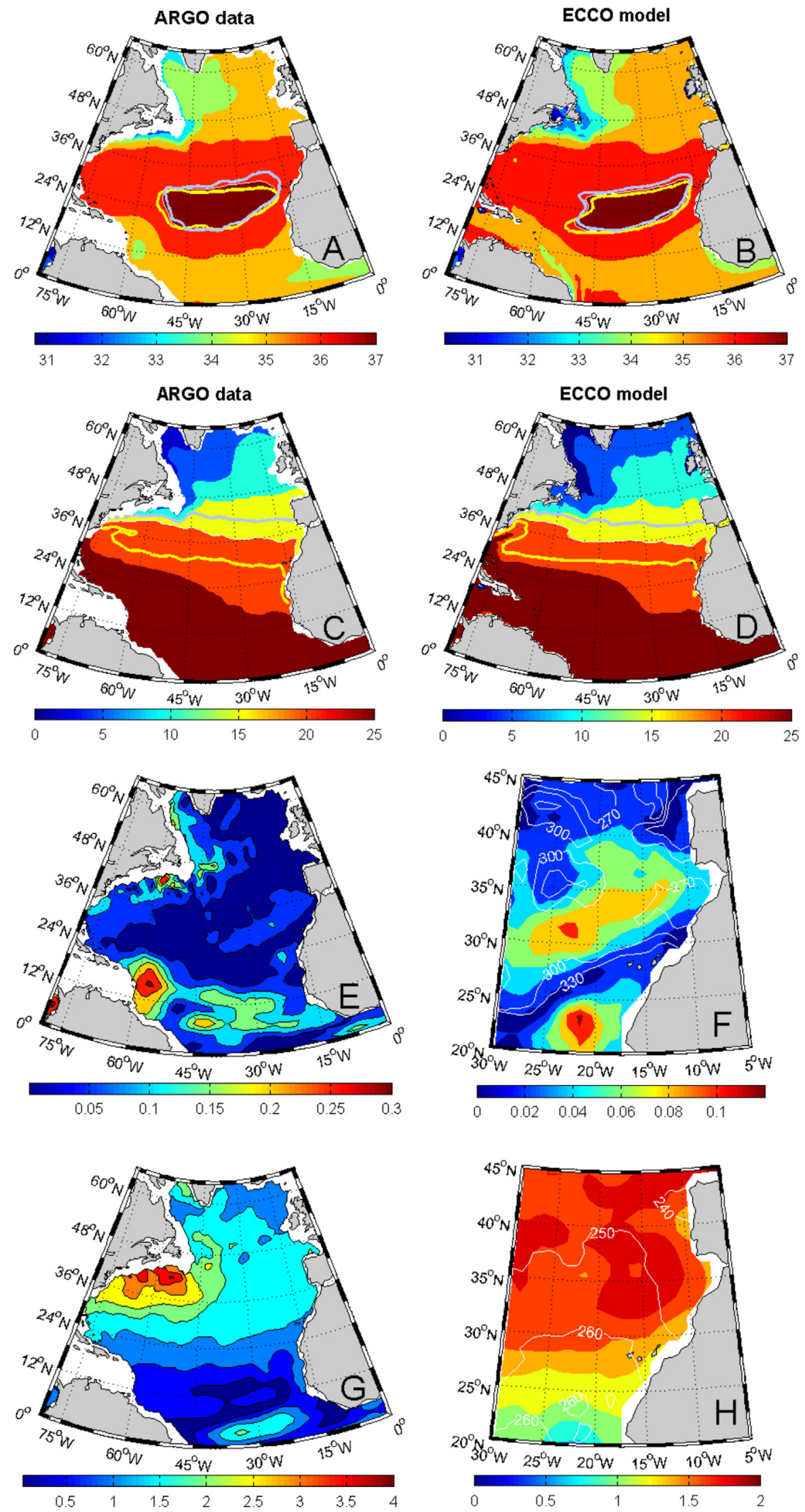

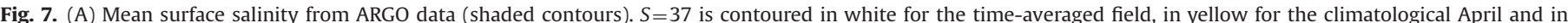

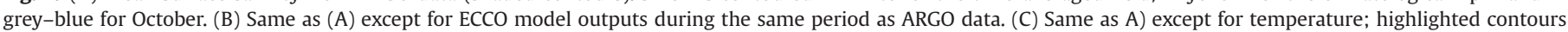

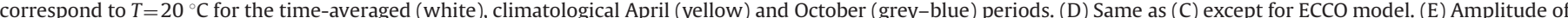

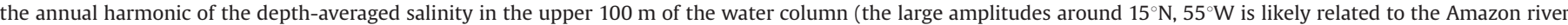

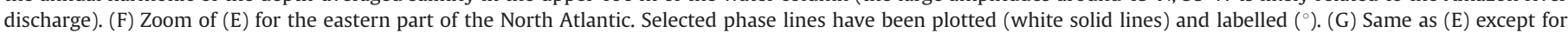

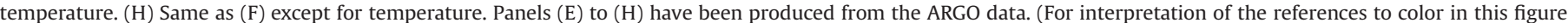
legend, the reader is referred to the web version of this article.) 


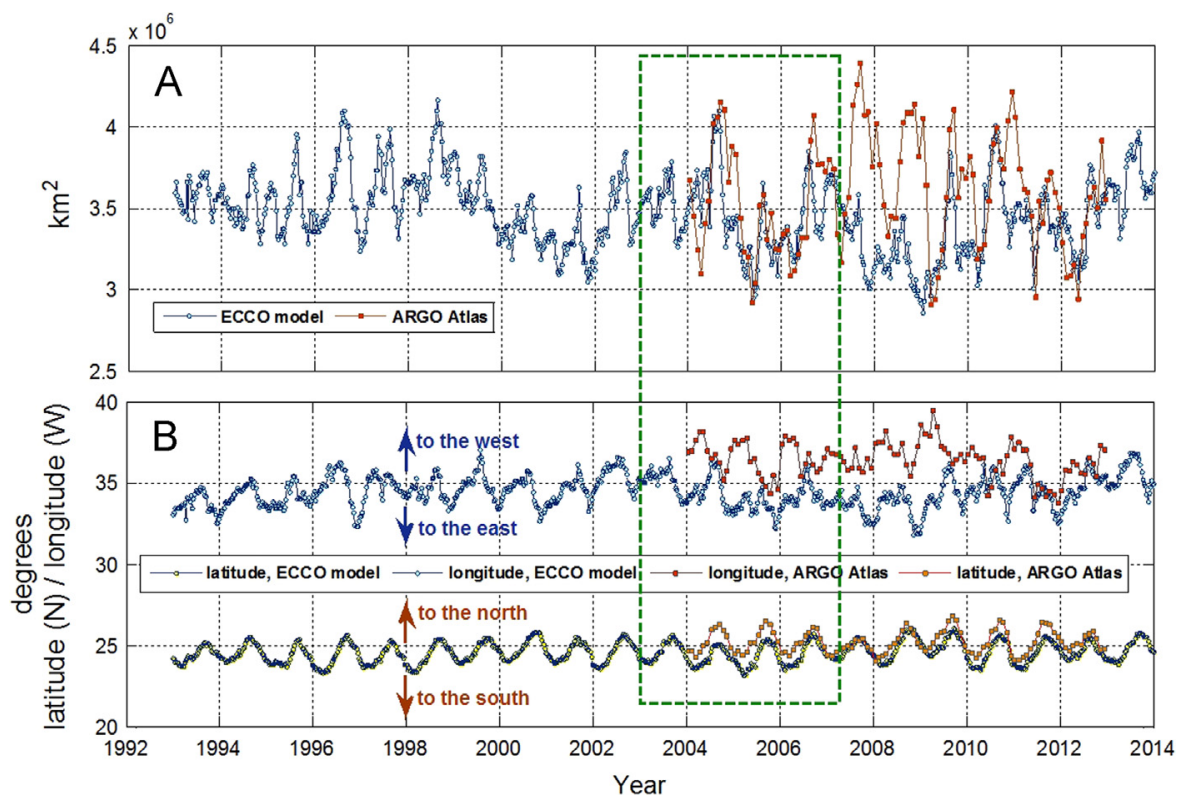

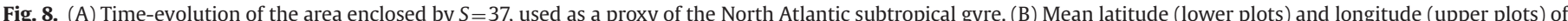

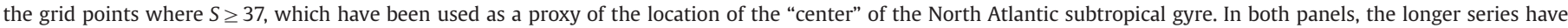

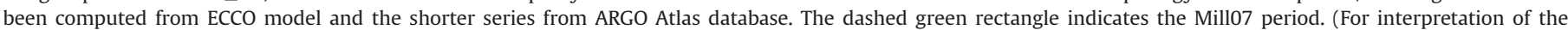
references to color in this figure legend, the reader is referred to the web version of this article.)
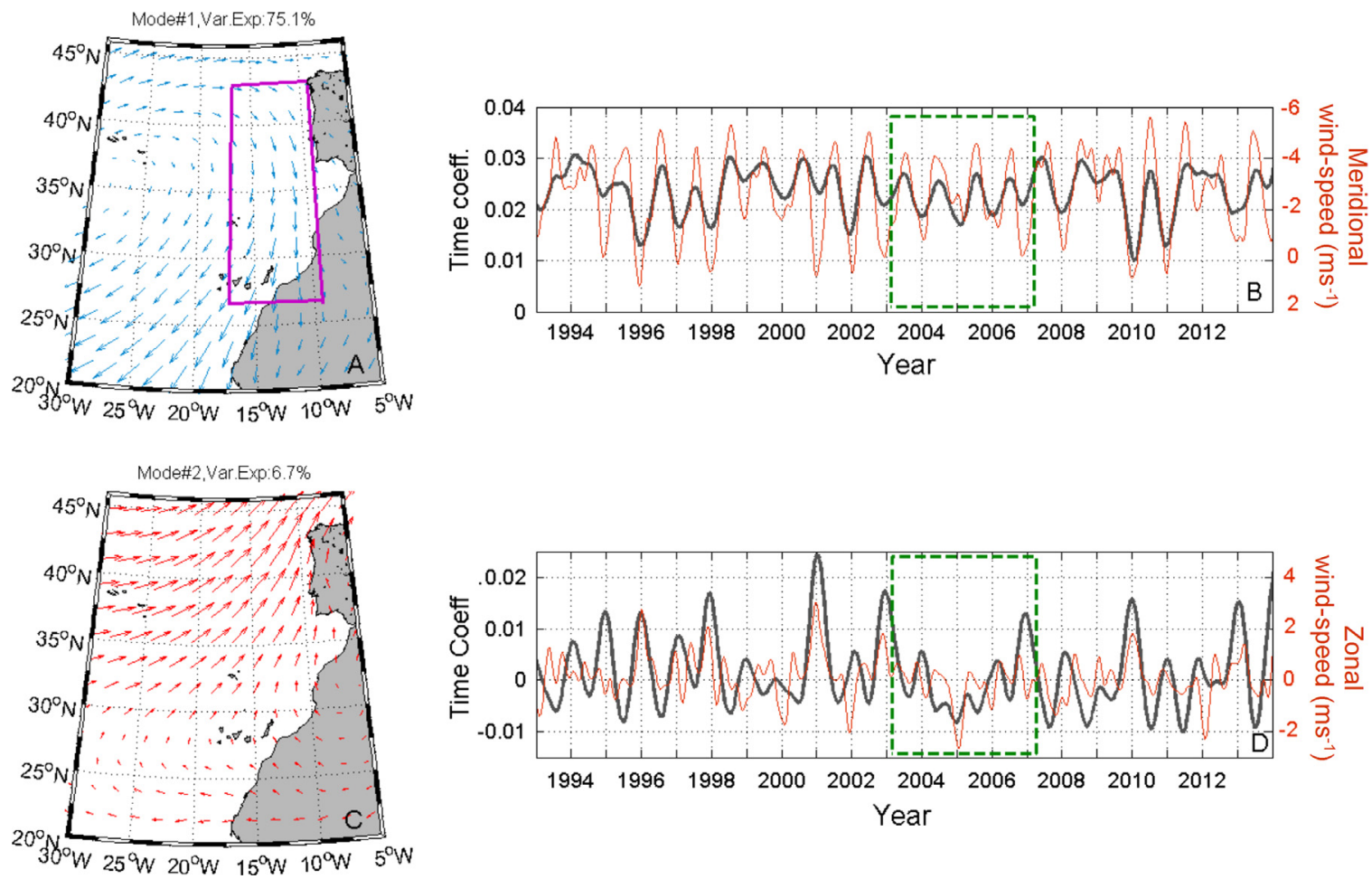

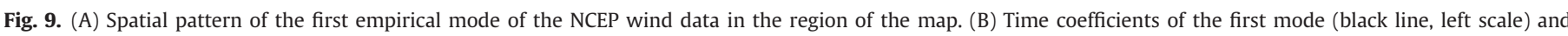

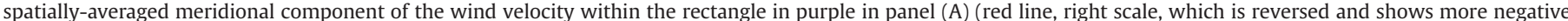

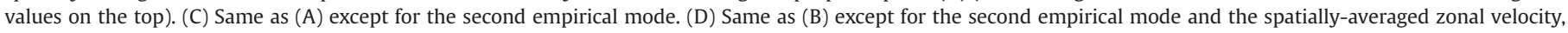

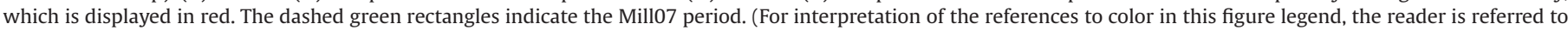
the web version of this article.)

highly correlated with the wind $(-0.79$, and +0.80 with the meridional and zonal components, respectively) and are a suitable proxy to follow the variability of the large scale wind field. For instance, they reach local maxima in summer, so depicting the wellknown intensification of the upwelling in this season. Time coefficients of mode \#2 are uncorrelated with the meridional component 


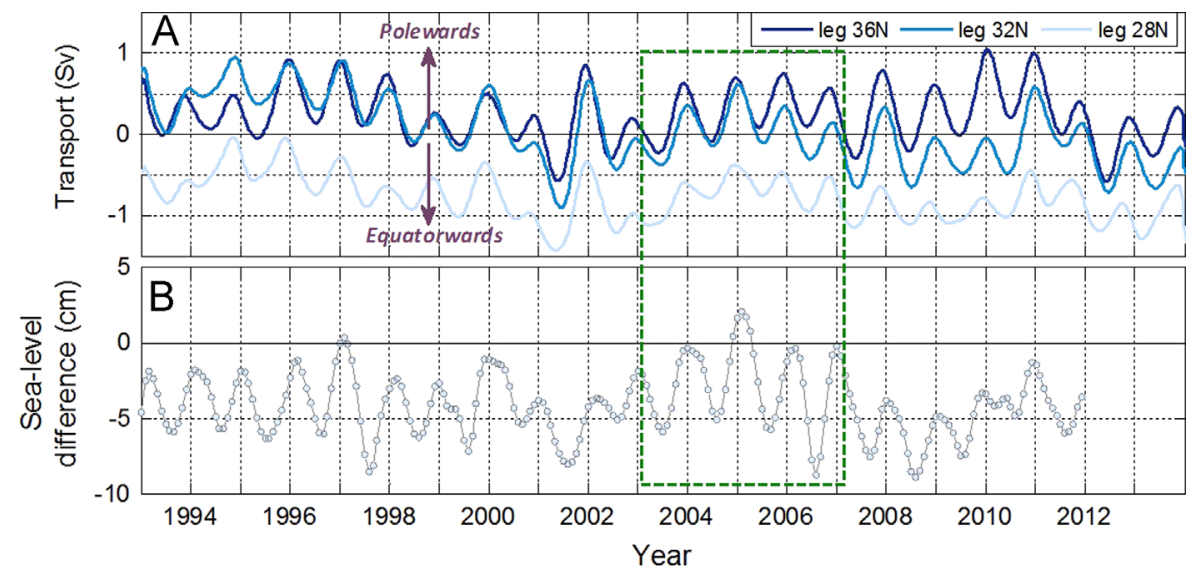

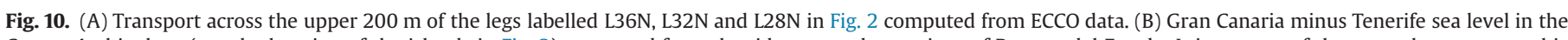

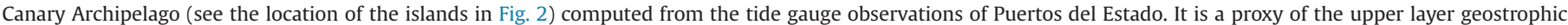

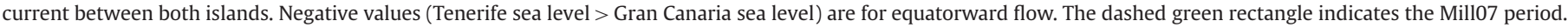

and only moderately correlated $(+0.58)$ with the zonal component, suggesting that this mode partially captures the zonal flow variability.

\subsection{The flow variability at the eastern North Atlantic}

\subsubsection{The horizontal advection: Meridional transports at the eastern boundary}

The meridional transports in the upper $200 \mathrm{~m}$ of the water column through the three selected zonal sections displayed in Fig. 2 have been computed using ECCO data and displayed in Fig. 10A. They illustrate the spatial and temporal variability of the circulation pattern in this area. Regarding the temporal variability, the transports show the expected seasonal fluctuations with increased equatorward (or greatly reduced poleward transport, depending on the section) during summer, the upwelling season, and enhanced poleward (or reduced equatorward transport, depending again on the section) during winter. The pattern is the foreseeable oceanic response to the wind forcing and, therefore, the transports are expected to be correlated with the mode \#1 time coefficients. The correlation is particularly good for the leg at $36^{\circ}(r=-0.75)$ and diminishes for the legs at $32^{\circ} \mathrm{N}$, and $28^{\circ} \mathrm{N}$ $(-0.46$ and -0.44 , respectively). The transports are also satisfactorily correlated (coefficients between 0.53 and 0.65 ) with the observed sea-level difference between Tenerife and Gran Canaria islands (Fig. 10B), which is a geostrophic proxy of the Canary Current (García-Lafuente et al., 2004), although the sea-level difference lags by $\sim 1.5$ months the computed transport.

Regarding the spatial pattern, Fig. 10A shows that the sign of the mean transport changes from the north to the south. Across $36^{\circ} \mathrm{N}$, it is poleward $(0.24 \mathrm{~Sv}$ with $0.33 \mathrm{~Sv}$ std $)$, while it is equatorward across $28^{\circ} \mathrm{N}\left(-0.77 \mathrm{~Sv}\right.$ with $0.28 \mathrm{~Sv}$ std). At $32^{\circ} \mathrm{N}$, it is nearly null with high variability ( $0.05 \mathrm{~Sv}, 0.42 \mathrm{~Sv}$ std). The pattern agrees with the presence of the poleward current off Iberia reported in Haynes and Barton (1990) and also with the cyclonic recirculation cells reproduced by the quasigeostrophic one-layer model of Machín et al. (2006) commented on in the Introduction. According to these authors, the seasonal meridional migration of the gyre would leave the GoC area under the influence of a cyclonic cell in winter with a northwards prevailing flow, and under the direct action of the Azores-Canary current transition in summer, when the flow would veer locally to the south.

The spatial-temporal variability illustrated in Fig. 10A agrees with the conclusions of Stramma and Isemer (1988), who found the variability in the eastern North Atlantic strongly dependent on latitude because the Ekman transport shows large seasonal fluctuations north of $25^{\circ} \mathrm{N}$. Interestingly, the spatial pattern of the seasonal signal in Fig. 7E and F displays a noticeable increase of the amplitude in the eastern North Atlantic north of $25^{\circ} \mathrm{N}$ as well. On the other hand, Fig. 7 shows that near the GoC area the horizontal salinity gradient heads to the north-northeast, so a poleward flow advects saltier water into the GoC area, whereas an equatorward flow advects fresher water from the north. The phase of the resulting seasonal salinity signal will match the one of ARGOGoC series in Fig. 4 since the poleward transport peaks by the end of the year, whereas the minimum poleward (or maximum equatorward, depending on the year and/or section) is detected in summer.

\subsection{The vertical advection: Ekman pumping in the Gulf of Cadiz}

Wind can change the local salinity at a given depth by inducing upwelling or downwelling. It physically happens through the Ekman pumping velocity, $w_{E K}$, the vertical velocity at the bottom of the surface Ekman layer, which is given by

$W_{E K}=\frac{1}{\rho} \overrightarrow{\boldsymbol{n}_{z}} \cdot \nabla \times \frac{\overrightarrow{\boldsymbol{\tau}_{\boldsymbol{W}}}}{f}$

where $f$ is the Coriolis parameter and $\overrightarrow{\boldsymbol{\tau}_{\boldsymbol{W}}}=c_{D} \rho_{a} W \overrightarrow{\boldsymbol{W}}$ is the wind stress $\left(c_{D}=1.5 \times 10^{-3}\right.$ a non-dimensional drag coefficient, $\rho_{a}$ the air density and $\overrightarrow{\boldsymbol{W}}$ the wind velocity). This vertical velocity penetrates in the ocean interior and it usually is the dominant term of the interior's vertical velocity field. In the presence of a vertical salinity gradient, $w_{E K}$ advects salinity and promotes local salinity changes that can be employed to estimate vertical displacement of isohalines, as in García-Lafuente et al. (2008), who estimated a Mediterranean vein uplift of several tens of meters off Galicia in the northwestern corner of the Iberian Peninsula during the upwelling season.

Fig. $11 \mathrm{~A}$ shows the spatial distribution of the mean value of $w_{E K}$ during the period 1992-2013 in the eastern part of the North Atlantic. It depicts the well-known upwelling area that changes to downwelling west of the marked 0 -contour to remain so in the vast majority of the mid-latitude North Atlantic. Fig. 11C shows the time evolution of the spatially averaged $w_{E K}(t)$ in the GoC area, which is fully inside the region of mean upwelling. Notice that $w_{E K}(t)$ remains positive most of the time except for very short periods at the end of some years and that it reflects the expected upwelling seasonal cycle with maxima in summer and minima in winter. 
A

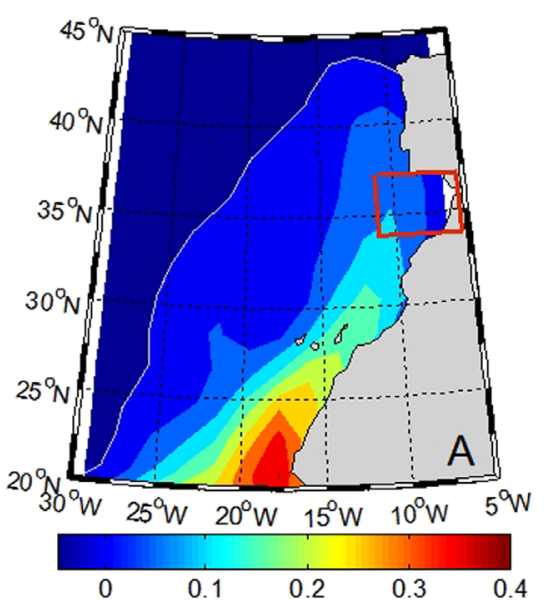

B

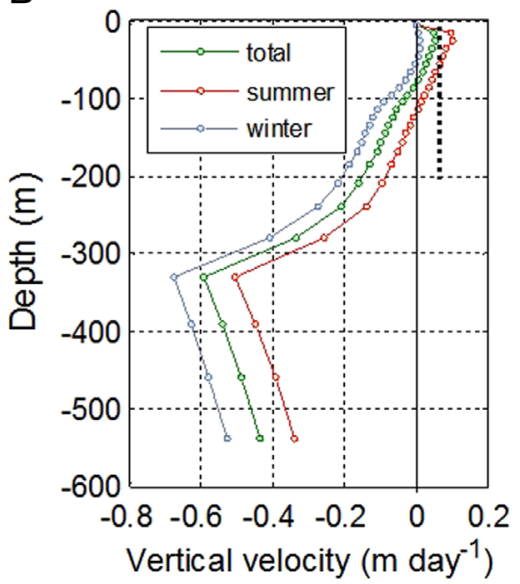

C

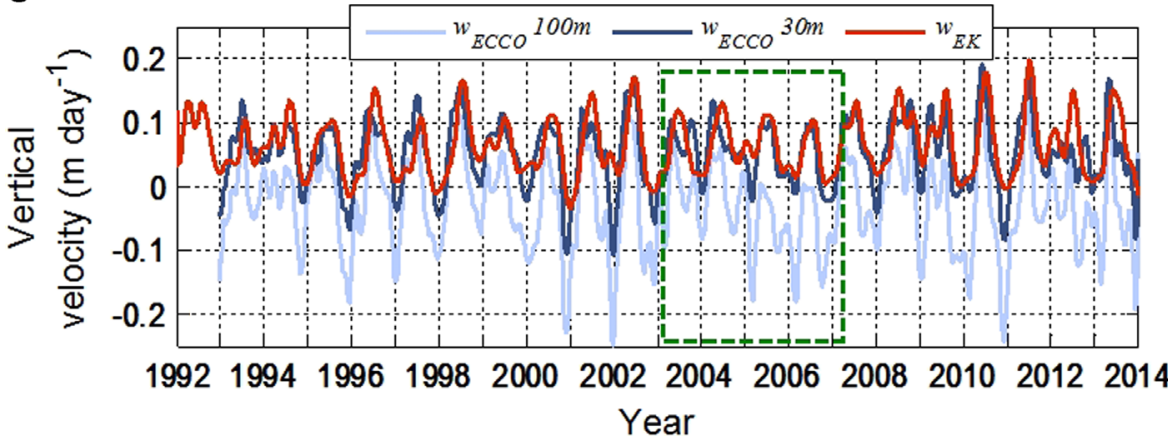

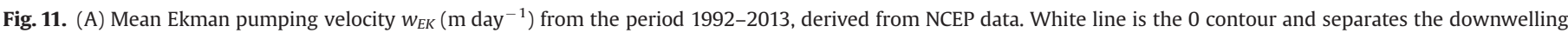

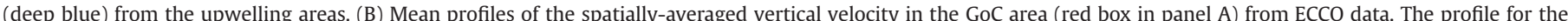

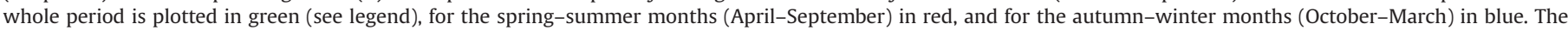

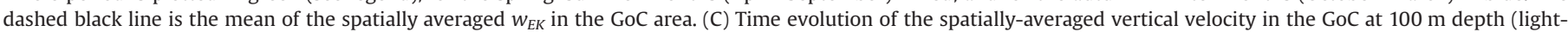

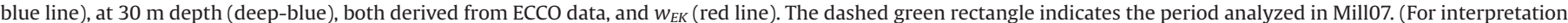
of the references to color in this figure legend, the reader is referred to the web version of this article.)

The presence of the Mediterranean outflow in the GoC complicates the pattern of the vertical velocity, which may differ from $w_{E K}$ noticeably as illustrated in Fig. 11B. This energetic outflow entrains a great volume of the overlying NACW as it leaves the Strait of Gibraltar and gives rise to downward velocity at intermediate depths (Peliz et al., 2009), which competes with the prevailing upwards $w_{E K}$ in the upper layer. The importance of this downwards flow has been emphasized by Johnson and Stevens (2000), who showed that the transport in the Azores Current is directly related to the strength of the Mediterranean outflow in the GoC, or Jia (2000), who even suggested that the primary mechanism for the formation of the Azores Current is water mass transformation associated with the entrainment of NACW by this overflow.

Fig. 11B shows that the maximum downwards velocity is found slightly deeper than $300 \mathrm{~m}$, which coincides with the depth of the upper boundary of the Mediterranean outflow just west of the Strait of Gibraltar, the place where the flow is more energetic and the downward entrainment more pronounced (Baringer and Price, 1997). The forced downwards flow changes the sign of the averaged wind-induced upwelling velocity at $\sim 80 \mathrm{~m}$ depth (Fig. 11B), although the zero crossing undergoes seasonal fluctuations of tens of meters. The upwelling layer thickens to $\sim 120 \mathrm{~m}$ during the upwelling season and nearly disappears in the winter months. The vertical velocity at $30 \mathrm{~m}$ depth given by the ECCO model (Fig. 11C) shows a good agreement with $w_{E K}$, better in summer when the upwelling layer is thicker. The vertical velocity at $100 \mathrm{~m}$ depth is prevailingly negative with positive episodes during the summer when the wind-inducing upwelling intensifies.
Regardless of its sign, the vertical velocities in Fig. 11C oscillate in phase. In the presence of a vertical salinity gradient like the one shown in Fig. 3, they will induce similar seasonal cycles in the local salinity whose amplitude would depend on the depth. The validity of this reasoning requires that the vertical salinity gradient does not change sign, which is verified above the depth of the Mediterranean water influence. This depth would be $300-350 \mathrm{~m}$ according to Fig. 3, although the core of the Mediterranean plume in the GoC flows noticeably deeper. Above these depths, the cycles induced by the vertical advection of salinity will agree in phase with the ARGOGoC observations in Fig. 4.

\section{Short term trend during years 2003-2007}

After addressing the mechanisms that drive the seasonal cycle of the salinity in the $\mathrm{GoC}$, this section resumes the investigation of the salinity trends reported in Millot's (2007) paper. The dashed green rectangles in Figs. 8 to 12 delimitate the period 2003-2007 covered by the observations in Mill07 and illustrate the fact that many variables display stable short-term trends during this period, which have been summarized in Table 2. Previously, an attempt to assess the contribution of the salinity advection to the local salinity in the $\mathrm{GoC}$ has been carried out by assuming a balance between both terms in the salinity equation (Eq. (A.1) for $X \equiv S$ ):

$\frac{\partial S_{\mathrm{ADV}}}{\partial t}=-\overrightarrow{\boldsymbol{u}}_{H} \nabla_{H} S-w \frac{\partial S}{\partial z}$ 
A

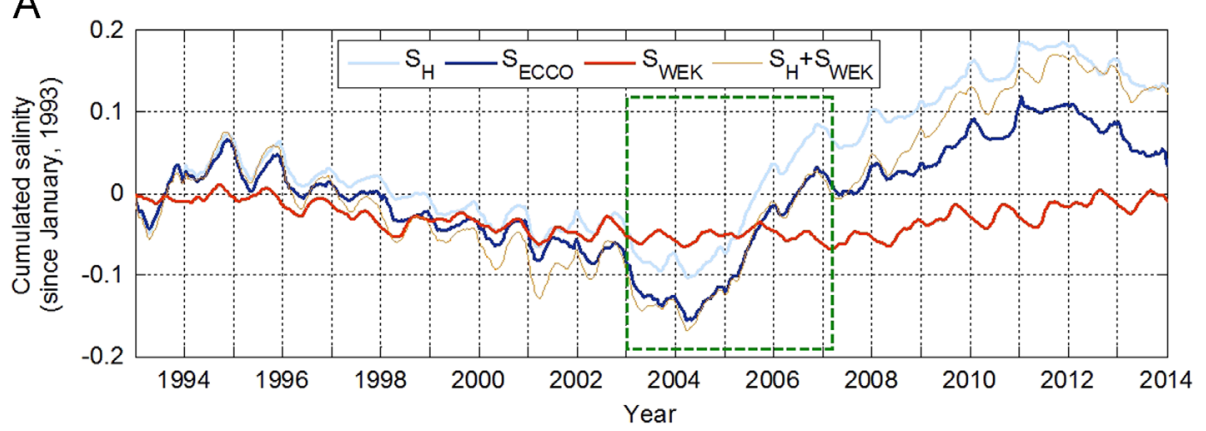

B

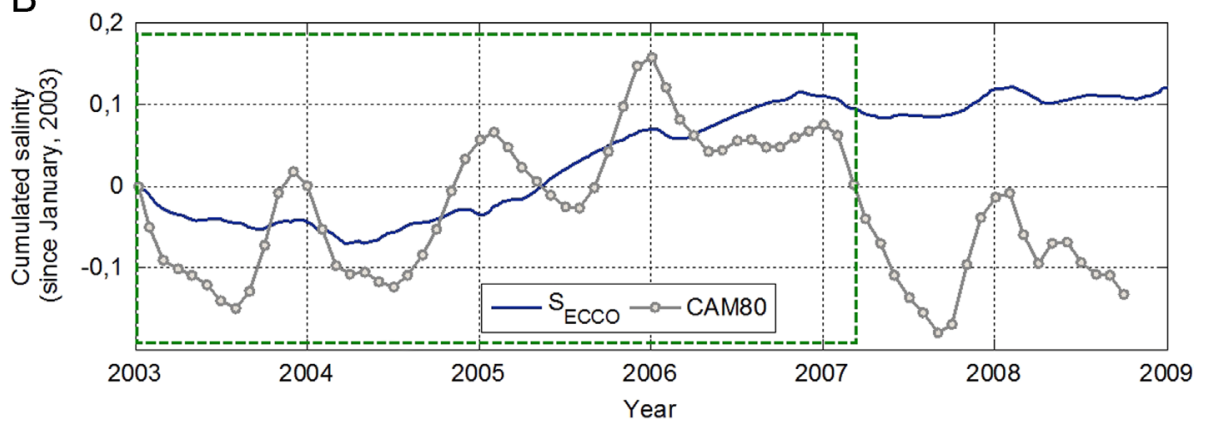

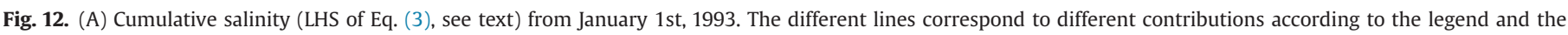

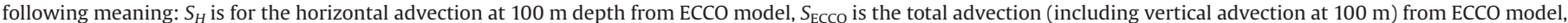

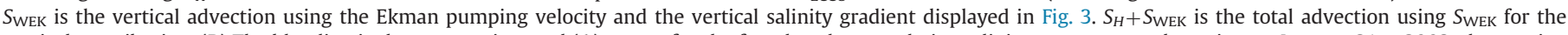

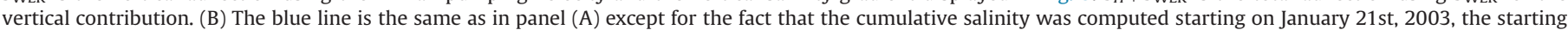

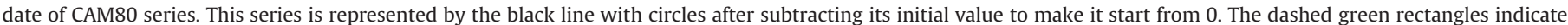
the period analyzed in Millo7. (For interpretation of the references to color in this figure legend, the reader is referred to the web version of this article.)

The horizontal and vertical contributions are written separately and subscript "ADV" remarks the fact that we refer to the contribution made by the advection to the local change exclusively. The equation can be integrated to give

$S_{\mathrm{ADV}}(t)=S_{0}-\int_{0}^{t} \overrightarrow{\boldsymbol{u}}_{H} \nabla_{H} S d t-\int_{0}^{t} w \frac{\partial S}{\partial z} d t$

where $S_{0}$ is the reference value at the initial instant $t=0$, which we have set arbitrarily to 0 , and the second and third terms of the RHS are the contributions of the horizontal and vertical advection, respectively. The RHS of Eq. (3) has been integrated numerically using the ECCO velocity and salinity fields. We have also used the Ekman pumping velocity (Eq. (1)) along with the salinity gradient $\partial S / \partial z=0.0026 \mathrm{~m}^{-1}$ deduced from Fig. 3 to carry out an alternate estimate of the vertical advection.

The results are presented in Fig. 12A, which shows how, besides the analyzed seasonal cycle, the total cumulated salinity in the $\mathrm{GoC}$ presents a longer-period cycle of nearly 20-year, whose minimum happens around year 2004 (deep-blue line). This date is very close to the start of Mill07 observations, suggesting that the short-term trend detected by Millot (2007) is the rising phase of the longer cycle. The main contributor to this cycle is the horizontal advection (light-blue line). Regarding vertical advection, the ECCO model provides a rather noisy signal whose effect is the negative linear trend identifiable in Fig. 12A by the steady increase with time of the difference between the horizontal (lightblue) and total (deep-blue) advection. The cause of the noisy signal is the very small vertical gradient of salinity produced by ECCO, significantly lower than its counterpart in ARGOGoC data (results not shown). For this reason we have carried out an independent estimate of the cumulated salinity originated by vertical advection using the Ekman pumping velocity and the ARGOGoC vertical salinity gradient of Fig. 3. The resulting series (red line) depicts a distinguishable seasonal oscillation superposed to a less important long cycle similar to the one of horizontal advection. The total cumulated salinity using this new estimate shows enhanced seasonal and long term cycles (thin brown line in Fig. 12A), although the difference with the previous computation during Mill07 period is negligible.

Fig. $12 \mathrm{~B}$ is a zoom of the period of CAM80 data with the cumulated salinity recalculated starting the integration at the beginning of year 2003. Although the short-term trend of CAM80 data during the Mill07 period is correctly reproduced (see Table 2), there are two differences that must be mentioned. The first one is the much greater amplitude of the seasonal cycle in Mill07 data, a discrepancy already visible in Fig. 5A and commented in Section 3.1, whose origin has been ascribed to the strong mixing in the Strait of Gibraltar. The second one refers to the drop of the salinity in CAM80 data after the Mill07 period (data outside the green rectangle in Fig. 12B), which is not well replicated by the simulated series, nor is the drop seen in the ARGOGoC data (Fig. 4). A satisfactory answer for the discrepancy is therefore lacking. A closer inspection to Fig. 1A, however, shows a progressive salinity diminution in the upper range of salinity ( 38.5$)$ after March 2007, when CAM80 station was serviced. Apparently, the decreasing trend could affect the whole range of salinities, for what an uncorrected drift of the salinity sensor cannot be disregarded as the source of the discrepancy.

Table 2 summarizes the short-term trends of relevant variables discussed in this study during the Mill07 period. Besides information concerning these variables, Table 2 includes in the last column a short interpretation of the expected consequences of the estimated trend if it were the case. The main driver of the short-term salinity trend appears to have been the wind field (Fig. 9, Block 4 of Table 2), whose meridional component showed a clear positive trend of $+0.21 \mathrm{~ms}^{-1}$ toward the north that weakened the prevailing equatorward wind during the Mill07 period, as confirmed by the time coefficients of the first EOF mode of the wind field. A consequence in 
Table 2

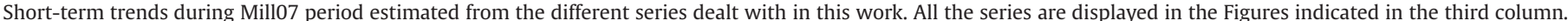

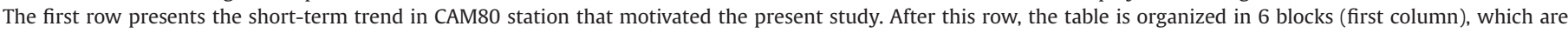
separated by double horizontal lines. Each block contains related variables that have been discussed in the different sections of the manuscript.

\begin{tabular}{|c|c|c|c|c|c|}
\hline Block & $\begin{array}{l}\text { Variable } \\
\text { Salinity at CAM80 }\end{array}$ & $\begin{array}{l}\text { Trend } \\
\mathbf{0 . 0 4 6}[\mathrm{psu}] \text { year }^{-1}\end{array}$ & $\begin{array}{l}\text { Figure/symbol } \\
\text { 12B/CAM80 }\end{array}$ & $\begin{array}{l}\text { Source } \\
\text { CAM80 Observations }\end{array}$ & $\begin{array}{l}\text { Effect/comment } \\
\text { Short-term trend detected in Millo7 data (subseries of CAM80) }\end{array}$ \\
\hline \multirow[t]{2}{*}{1} & $\begin{array}{l}\text { GoC salinity }(50- \\
100 \mathrm{~m})\end{array}$ & $0.012[\mathrm{psu}]$ year $^{-1}$ & $\begin{array}{l}4 \mathrm{~A}, \mathrm{~B} / 50-100 \mathrm{~m} \\
\text { Table } 1\end{array}$ & ARGOGoC & Data do not span the whole Mill07 period \\
\hline & $\begin{array}{l}\text { GoC salinity (100- } \\
150 \mathrm{~m})\end{array}$ & $0.010[\mathrm{psu}]$ year $^{-1}$ & $\begin{array}{l}4 \mathrm{~A}, \mathrm{~B} / 100-150 \mathrm{~m} \\
\text { Table } 1\end{array}$ & ARGOGoC & Data do not span the whole Mill07 period \\
\hline \multirow[t]{4}{*}{2} & Horizontal advection & $0.047[\mathrm{psu}] \mathrm{year}^{-1}$ & $12 \mathrm{~A} / \mathrm{S}_{\mathrm{H}}$ & Ecco model & \\
\hline & Total advection ${ }^{\mathrm{a}}$ & $0.044[\mathrm{psu}]$ year $^{-1}$ & $12 \mathrm{~A}, \mathrm{~B} / S_{\mathrm{ECCO}}$ & Ecco model & \\
\hline & Vertical advection $^{\mathrm{b}}$ & $0.003[\mathrm{psu}]$ year $^{-1}$ & $12 \mathrm{~A} / S_{\text {WEK }}$ & $\begin{array}{l}\text { Ekman pumping (wind } \\
\text { NCEP) }\end{array}$ & \\
\hline & Total advection ${ }^{\mathrm{c}}$ & $0.048[\mathrm{psu}]$ year $^{-1}$ & $12 \mathrm{~A} / S_{H}+S_{\mathrm{WEK}}$ & $\begin{array}{l}\text { Ecco model }+ \text { Ekman } \\
\text { pumping }\end{array}$ & \\
\hline \multirow[t]{6}{*}{3} & EW displac. NASG & $-0.37^{\circ}$ year $^{-1}$ & $8 \mathrm{~B}$ & Ecco model & $\begin{array}{l}\text { Westward shift of NASG, the horizontal salinity gradient } \\
\text { increases near GoC }\end{array}$ \\
\hline & EW displac. NASG & $-0.23^{\circ}$ year $^{-1}$ & $8 \mathrm{~B}$ & ARGO data & $\begin{array}{l}\text { Same meaning as previous row. Data do not span the whole } \\
\text { Mill07 period }\end{array}$ \\
\hline & $\mathrm{N}-\mathrm{S}$ displac. NASG & $0.03^{\circ}$ year $^{-1}$ & $8 \mathrm{~B}$ & Ecco model & Trend not statistically significant \\
\hline & $\mathrm{N}-\mathrm{S}$ displac. NASG & $0.005^{\circ}$ year $^{-1}$ & $8 \mathrm{~B}$ & ARGO data & $\begin{array}{l}\text { Trend not statistically significant. Data do not span the whole } \\
\text { Mill07 period }\end{array}$ \\
\hline & Area $S>37$ NASG & $\begin{array}{l}-0.03 \\
10^{6} \mathrm{~km}^{2} \text { year }^{-1}\end{array}$ & $8 \mathrm{~A}$ & Ecco model & $\begin{array}{l}\text { Diminution of the area of the NASG (linked to its westward } \\
\text { shift?) }\end{array}$ \\
\hline & Area $S>37$ NASG & $\begin{array}{l}-0.01 \\
10^{6} \mathrm{~km}^{2} \text { year }^{-1}\end{array}$ & $8 \mathrm{~A}$ & ARGO data & $\begin{array}{l}\text { Trend not statistically significant. Data do not span the whole } \\
\text { Mill07 period }\end{array}$ \\
\hline \multirow[t]{3}{*}{4} & $\begin{array}{l}\mathrm{N}-\mathrm{S} \text { wind-speed in } \\
\text { ENA }\end{array}$ & $\begin{array}{l}+0.21\left(\mathrm{~m} \mathrm{~s}^{-1}\right) \\
\text { year }^{-1}\end{array}$ & 9B & NCEP-NCAR & $\begin{array}{l}\text { Decreasing equatorward wind-speed. Weakening of the } \\
\text { upwelling }\end{array}$ \\
\hline & $\begin{array}{l}\text { E-W wind-speed in } \\
\text { ENA }\end{array}$ & $\begin{array}{l}-0.02\left(\mathrm{~m} \mathrm{~s}^{-1}\right) \\
\operatorname{year}^{-1}\end{array}$ & 9D & NCEP-NCAR & Trend not statistically significant \\
\hline & $\begin{array}{l}\text { Mode \#1 EOF wind } \\
\text { field }\end{array}$ & $1.310^{-4}$ year $^{-1}$ & $9 \mathrm{~B}$ & NCEP-NCAR & Weakening of the spatial pattern of mode $\# 1$ \\
\hline \multirow[t]{3}{*}{5} & Transport $36 \mathrm{~N}$ & $0.1 \mathrm{~Sv}_{\text {year }}{ }^{-1}$ & $10 \mathrm{~A} / \operatorname{Leg} 36 \mathrm{~N}$ & Ecco model & Increase of northward advection of salinity \\
\hline & Transport $32 \mathrm{~N}$ & 0.04 Sv year $^{-1}$ & $10 \mathrm{~A} / \mathrm{Leg} 32 \mathrm{~N}$ & Ecco model & Increase of northward advection of salinity \\
\hline & Transport $28 \mathrm{~N}$ & $0.07 \mathrm{~Sv}$ year $^{-1}$ & 1A/Leg28N & Ecco model & Increase of northward advection of salinity \\
\hline \multirow[t]{3}{*}{6} & Vertical velocity $30 \mathrm{~m}$ & $\begin{array}{l}-0.01\left(\mathrm{~m} \mathrm{day}^{-1}\right) \\
\text { year }^{-1}\end{array}$ & $11 \mathrm{C} / W_{\mathrm{ECCO}} 30 \mathrm{~m}$ & Ecco model & Upwelling reduction \\
\hline & $\begin{array}{l}\text { Vertical velocity } \\
100 \mathrm{~m}\end{array}$ & $\begin{array}{l}-0.02\left(\mathrm{~m} \mathrm{day}^{-1}\right) \\
\text { year }^{-1}\end{array}$ & $11 \mathrm{C} / W_{\mathrm{ECCO}} 100 \mathrm{~m}$ & Ecco model & Upwelling reduction \\
\hline & $\begin{array}{l}\text { Ekman pumping } \\
\text { velocity }\end{array}$ & $\begin{array}{l}-0.01\left(\mathrm{~m} \mathrm{day}^{-1}\right) \\
\text { year }^{-1}\end{array}$ & $11 C / w_{E K}$ & NCEP-NCAR & Upwelling reduction \\
\hline
\end{tabular}

a Total advection computed using the ECCO model fields.

${ }^{\mathrm{b}}$ Vertical advection using the Ekman pumping velocity and the salinity gradient of ARGOGoC

${ }^{\mathrm{c}}$ Total advection using the ECCO model for the horizontal and the Ekman pumping velocity for the vertical contributions.

the ocean response is the concomitant positive trend of the transport along the eastern boundary (Fig. 10, Block 5 of Table 2), which increased the northwards advection of salinity in the GoC. The process should be fed back by the eastwards drift of the North Atlantic subtropical gyre (Fig. 8, Block 3), which would make saltier water available for advection along the eastern boundary. On the other hand, the weakening of the equatorward winds would reduce the vertical velocity in the upwelling regions (Fig. 11, Block 6), allowing for the downward relaxation of isohalines and the subsequent local increase of salinity taking into account the sign of the vertical salinity gradient in Fig. 3.

\section{Summary and conclusions}

Observations collected by the CAM80 station revealed seasonality and a short-term salinity trend of the inflow through the SoG (Fig. 1C). Both of them were reported by Millot (2007), who focused on the interannual salinification of the inflow rather than on its seasonal signal. As shown by later observations, the salinification halted in year 2007 (Fig. 1C), revealing itself as a short-term trend that, curiously, spanned the first four years of the CAM80 observations analyzed in Mill07 study. It must be said that both features are only displayed after processing the observations to minimize the effect of the strong tidally-driven mixing held up by the inflow. It is not an easy task, and even doing the best to remove these unwanted effects, a residual contamination is likely to remain, which would overestimate the seasonal cycle in particular.

On the basis that the seasonal cycle and the interannual variability have the same external drivers, we have addressed first the more conspicuous seasonal signal to identify these drivers. We have focused on the salinity signal because it was the salinity recorded at CAM80 that motivated the present study, and also because the origin of the seasonal signal is more challenging for salinity than for temperature, the latter being almost entirely explained by the solar cycle.

Fig. 3 suggests that the waters flowing through CAM80 reside at $100-150 \mathrm{~m}$ depth in the $\mathrm{GoC}$, a depth range occupied by the NACW whose salinity diminishes with depth. In the Strait of Gibraltar area, its footprint is an absolute minimum of salinity (Fig. 3), a fact that explains why this water leaves a distinct seasonal signal in salinity rather than in temperature at CAM80. ARGO data ratify the obviousness that the signal comes from the GoC. When analyzed jointly with the NCEP-NCAR data, they confirm that the heat surface flux explains the temperature seasonal signal of the upper ocean. However, the freshwater flux does not do the same with the salinity. ECCO model and 
NCEP-NCAR data have been then used to investigate the role of the advective fluxes with the expected result that they represent a very minor contribution for temperature (Fig. 6A) but not for salinity (Fig. 6C and D).

Since advection is linked to the ocean dynamics, we have focused on the surface circulation pattern of the mid-latitude North Atlantic and on the wind-stress, its main driver, which is able to cause basin scale fluctuations of the circulation at annual and interannual time-scales (Eden and Willebrand, 2000; Machín et al., 2006). At seasonal time-scale, the wind-stress is responsible for the well-known seasonal upwelling in the eastern boundary (Wooster et al., 1976). On the other hand, employing the surface salinity of either ARGO or ECCO databases as a proxy suggests the existence of a seasonal cycle of the size and location of the North Atlantic subtropical gyre (Figs. 7 and 9) that influences the horizontal salinity gradient (and, hence, the advection) in the vicinity of the GoC. The seasonal cycle of the wind stress also originates a similar cycle of the meridional oceanic transport that peaks in winter (Fig. 10A). In terms of the horizontal advection, the cycle carries saltier water at subsurface depths nearby the GoC area, matching the observed increase of salinity during this part of the year (Fig. 5). The intensification/relaxation cycles of the windinducing upwelling generate a concomitant cycle of the Ekman pumping and of the vertical velocity in general (Fig. 11), whose related vertical advection matches the timing of the cycle deduced from ARGOGoC data.

The existence of the internal modes of the atmosphere distorts the wind stress seasonal cycle and gives rise to perceptible interannual variability. This was apparently the case during the Mill07 period when the wind-stress anomaly likely occasioned what we have called "short-term trend" throughout the study. Proofs for this trend have been searched for in the different series produced in this study and the results are summarized in Table 2. The analysis of these results carried out in Section 5 led to the conclusion that the reduction of the equatorward wind stress associated with a general weakening of the pattern of the wind field over the eastern North Atlantic triggered the trend. Therefore, either directly or indirectly, the cycle of the wind-stress is responsible for the fluctuations of the advective flux that, together with the surface fluxes, contribute to the local salinity changes in the GoC. And this is true for both seasonal and interannual timescales. Barton et al. (2013) pointed out that winds off Iberian Peninsula are becoming slightly less upwelling favorable, in which case the inflow through the Strait of Gibraltar would become slightly saltier. Should the tendency be maintained in time, the influence of the extra-accumulation of salt into the Mediterranean Sea will have consequences for its thermohaline circulation. To this regard, the relevant question of whether or not the short-term trend in CAM80 series, collected at $80 \mathrm{~m}$ depth, may be extrapolated to the sea surface finds a partial answer in the last column of Table 1. It shows that the whole water column above $200 \mathrm{~m}$ displays a positive trend, which even is enhanced in the more superficial layer.

Finally an attempt was made to find correlations between the SMcam series and the climatic indices that measure the variability of the atmosphere, a correlation that should be established via the wind-stress. Although the NAO is the dominant atmospheric mode of natural variability in the North Atlantic (Eden and Willebrand, 2000), the correlation found between this index and SMcam salinity series is not significantly different from zero. Using the EA index the correlation improves to a significant value of 0.35 at a lag of 5 months. As showed by Criado-Aldeanueva et al. (2014), the atmospheric sea level pressure anomalies associated with the EA index in the eastern North Atlantic show a spatial pattern closely related to the geostrophic meridional winds off Iberia and North Africa and this would explain the better performance of the EA index in our case. Nevertheless, the correlation is low and the length of SMcam too short to draw definitive conclusions.

\section{Acknowledgments}

We acknowledge ARGO the International ARGO Program (http://www.argo.ucsd.edu), which is part of the Global Ocean Observing System, the freely available data collected by ARGO floats. We also acknowledge the Consortium for Estimating the Circulation and Climate of the Ocean (ECCO, http://crab.jpl.nasa. gov/thredds/catalog/las/) funded by the National Oceanographic Partnership Program for making ECCO data freely available. The CAM80 monitoring station is part of the Mediterranean Sea monitoring network Hydro-Changes, sponsored by the CIESM (http://www.ciesm.org/marine/programs/hydrochanges.htm). Sea level data at Tenerife and Gran Canaria ports were collected by the REDMAR network of Puertos del Estado (Spain) and downloaded from the Institution website for free. This work was funded by the Spanish Ministry of Economy Competitiveness under Research Project INGRES-3 (CTM2010-21229). CN acknowledges the fellowship BES-2011-043421 and JCSG the Juan de la Cierva Postdoctoral Grant JCI-2012-13451 from that Ministry. This is the publication no. 90 from Ceimar Publication Series.

\section{Appendix A. The integral form of the advection-diffusion equation}

The standard formulation of the advection-diffusion equation for a generic tracer $X$ is

$\frac{\partial X}{\partial t}+\overrightarrow{\boldsymbol{u}} \nabla X=\nabla\left(\kappa_{X} \nabla X\right)$

where $\kappa_{X}$ is the eddy-diffusion coefficient. If $X \equiv T$, temperature, multiplying Eq. (A.1) by $\left(\rho c_{p}\right), \rho$ the seawater density and $c_{p}$ its specific heat capacity at constant pressure, results in the heat energy equation. Sources per volume unit that should appear in the RHS (viscous dissipation in case of $T$, for instance) are usually negligible and are not included. As far as seawater is incompressible, Eq. (A.1) can be rewritten in its conservative formulation

$\frac{\partial X}{\partial t}=\nabla\left(-X \overrightarrow{\boldsymbol{u}}+\kappa_{X} \nabla X\right)$

where the first and second terms of the RHS are the advective and the diffusive fluxes, respectively. Written in this form, the equation is suitable for applying the Gauss' theorem within a control volume $V$. The theorem states that for any vector, the volume integral of its divergence is equal to the integral of the flux over the enclosing surface. Choosing as a control volume a prism of height $h$ whose top lid is the free surface, the theorem enables the explicit inclusion of surface fluxes in the resulting equations (heat and freshwater in case of temperature and salinity, respectively), which otherwise cannot be included in the differential forms of Eq. (A.1) or Eq. (A.2) since they are not sources per volume unit. The integration of Eq. (A.2) over $V$ and the application of the Gauss' theorem yield an expression for the evolution of $X$ in the control volume as a function of the fluxes entering/leaving the volume through the enclosing surface, including the surface fluxes, $\vec{F}_{\boldsymbol{X}}$ :

$\frac{\partial}{\partial t} \iiint_{\text {vol }} X d V=\iint_{\text {surface }}\left(-X \overrightarrow{\boldsymbol{u}}+\kappa_{X} \nabla \mathbf{X}+\overrightarrow{\boldsymbol{F}}_{X}\right) d S$

For typical values of eddy-diffusivity in the open ocean $\left(\kappa_{X} \mathrm{O}\left(10^{3}\right)-\mathrm{O}\left(10^{4}\right) \mathrm{m}^{2} \mathrm{~s}^{-1}\right.$ for temperature and salinity, Bates et al. (2014)), the diffusive fluxes (second term in the RHS) are much less than the advection and/or surface fluxes (first and third terms of the RHS) and can be neglected. The surface flux term $\vec{F}_{X}$ in the case of the 
temperature equation is

$\overrightarrow{\boldsymbol{F}}_{T}=\frac{1}{\rho c_{p}} \dot{Q}_{\text {net }} \overrightarrow{\boldsymbol{n}}_{z}$

where $\dot{Q}_{\text {net }}$ is the net heat flux and $\overrightarrow{\boldsymbol{n}}_{\boldsymbol{z}}$ is the vertical unit vector. $\overrightarrow{\boldsymbol{F}}_{T}$ has units of ${ }^{\circ} \mathrm{Cm} \mathrm{s}^{-1}$.

\section{Appendix B. The surface flux term for salinity}

Eq. (A.3) is also valid for salinity with the appropriate surface flux $\overrightarrow{\boldsymbol{F}}_{S}$ term, whose explicit expression is less obvious than in the case of temperature. To find an expression for $\overrightarrow{\boldsymbol{F}}_{s}$, let us consider a water column $h$ meters high and ignore the advection and diffusion terms. The only mechanism available for changing the salinity in the control volume is the freshwater flux across the surface $(E-P)$, expressed as a mass flux $\left(\mathrm{kg} \mathrm{m}^{-2} \mathrm{~s}^{-1}\right)$. In a time interval $\Delta t=t_{2}-t_{1}$ the height $h$ of the control volume will have changed by

$\Delta h=\frac{1}{\rho_{0}} \int_{t_{1}}^{t_{2}}(E-P) d t=\frac{\overline{(E-P)}}{\rho_{0}} \Delta t$

where $\rho_{0}$ is the freshwater density and $\overline{(E-P)}$ is the net timeaveraged evaporation during $\Delta t$. Since only freshwater is exchanged, the amount of salt inside the control volume does not change. At instant $t_{1}$ it is proportional to $\bar{S}\left(t_{1}\right) h$, where $\bar{S}$ is the depth-averaged salinity

$\bar{S}\left(t_{1}\right)=\frac{1}{h} \int_{-h}^{0} S\left(z, t_{1}\right) d z$

whereas at time $t_{2}$ it will be proportional to $\bar{S}\left(t_{2}\right)(h-\Delta h)$. Salt conservation implies $\bar{S}\left(t_{1}\right) h=\bar{S}\left(t_{2}\right)(h-\Delta h)$, from which $\Delta h$ can be written in terms of the salinity difference $\Delta \bar{S}=\bar{S}\left(t_{2}\right)-\bar{S}\left(t_{1}\right)$

$\Delta h=\frac{\Delta \bar{S}}{\bar{S}\left(t_{2}\right)} h \approx \frac{\Delta \bar{S}}{S_{0}} h$

In (B.3), $\bar{S}\left(t_{2}\right)$ has been replaced by a reference salinity $S_{0}$ because $\Delta \bar{S} \ll \bar{S}\left(t_{2}\right)$. Equating (B.1) and (B.3)

$h \frac{\Delta \bar{S}}{\Delta t}=\frac{S_{0}}{\rho_{0}} \overline{(E-P)}$

Making $\Delta t \rightarrow 0$, the LHS of Eq. (B.4) becomes the LHS of the salinity version of Eq. (A.3) for a control volume of unit surface area and height $h$, and $\overline{(E-P)}$ coincides with $(E-P)$ at instant $t_{1}$. Therefore, under the hypothesis of neither advection nor diffusion, the surface flux term in the salinity equation must be

$\overrightarrow{\boldsymbol{F}}_{S}=\frac{S_{0}}{\rho_{0}}(E-P) \overrightarrow{\boldsymbol{n}}_{z}$

in order to satisfy Eq. (B.4). Its units are [psu] $\mathrm{m} \mathrm{s}^{-1}$, or $\mathrm{m} \mathrm{s}^{-1}$ strictly speaking.

\section{Appendix C. Computation of local variations and surface fluxes from the data}

The heat content in a prismatic control volume of unit horizontal area and $h$ meters high is

$H_{C}=\int_{-h}^{0} \rho c_{p} T d z$ and the variation of the heat content between $t_{1}$ and $t_{2}$, $\Delta H_{C}=H_{C}\left(t_{2}\right)-H_{C}\left(t_{1}\right)$, will be

$\Delta H_{C}=\int_{-h}^{0} \rho c_{p}\left[T\left(z, t_{2}\right)-T\left(z, t_{1}\right)\right] d z$

whereas the heat per unit area $H_{S}$ transferred from the atmosphere to the control volume during the same time interval will be

$H_{S}=\int_{t_{1}}^{t_{2}} \dot{Q}_{n e t} d t$

If advection and diffusion are ignored, then Eq. (C.2) must be balanced by Eq. (C.3) in Eq. (A.3) in the case of temperature. Both expressions are readily computed from ARGO (or ECCO) and NCEP datasets, respectively

A similar approach can be worked up for salinity. The depthaveraged salinity at instant $t_{1}$ is given by Eq. (B.2). The change of depth averaged salinity $\Delta \bar{S}=\bar{S}\left(t_{2}\right)-\bar{S}\left(t_{1}\right)$ between $t_{1}$ and $t_{2}$ will be

$\Delta \bar{S}=\frac{1}{h-\Delta h} \int_{-h}^{-\Delta h} S\left(z, t_{2}\right) d z-\frac{1}{h} \int_{-h}^{0} S\left(z, t_{1}\right) d z \approx \frac{1}{h} \int_{-h}^{0}\left[S\left(z, t_{2}\right)-S\left(z, t_{1}\right)\right] d z$

where $\Delta h$ is the thickness of the freshwater layer removed/added by the net evaporation during $\Delta t=t_{2}-t_{1}$ in the unit area prism. The relationship between $\Delta h$ and $(E-P)$ is given by Eq. (B.1) with the implicit convention that $\Delta h$ is positive if evaporation exceeds precipitation and negative otherwise (hence the sign of $\Delta h$ in the intermediate step in Eq. (C.4)). Taking into account that $(E-P)$ in mid latitudes is $\sim 1 \mathrm{~m}$ year $^{-1}$ and that the interval $\left(t_{1}, t_{2}\right)$ is one month in the ARGOGoC data, $\Delta h$ in Eq. (B.1) will be less than $0.1 \mathrm{~m}$, which justifies the approximation carried out in Eq. (C.4) where $\Delta h$ does not appear any more in the RHS.

The salinity variation between $t_{1}$ and $t_{2}$ inside the unit area control volume is $h \Delta \bar{S}$, which must be compared with the salinity flux per unit area across the sea surface (time integral of Eq. (B.5))

$\bar{S}_{E}=\frac{S_{0}}{\rho_{0}} \int_{t_{1}}^{t_{2}}(E-P) d t$

Again, if advection and diffusion are ignored, then Eq. (C.4) must be balanced by Eq. (C.5) in equation Eq. (A.3) in the case of salinity, and both terms are easily computed from our datasets.

\section{References}

Adloff, F., Somot, S., Sevault, F., Jorda, G., Aznar, R., Deque, M., Herrmann, M. Marcos, M., Dubois, C., Padorno, E., Alvarez-Fanjul, E., Gomis, D., 2015 Mediterranean Sea response to climate change in an ensemble of twenty first century scenarios. Clim. Dyn. , http://dx.doi.org/10.1007/s00382-015-2507-3.

Baringer, M.O., Price, J.F., 1997. Mixing and spreading of the Mediterranean outflow. J. Phys. Oceanogr. 27, 1657-1677.

Barton, E.D., 1998. Eastern boundary of the North Atlantic: Northwest Africa and Iberia. In: Brink, K.H., Robinson, A.R. (Eds.), The Sea. The Global Coastal Ocean: Regional Studies and Syntheses, vol. 11. Harvard Univ. Press, New York, NY pp. 633-657.

Barton, E.D., Field, D.B., Roy, C., 2013. Canary current upwelling: more or less? Prog. Oceanogr. 116, 167-178. http://dx.doi.org/10.1016/j.pocean.2013.07.007.

Bates, M., Tulloch, R., Marshall, J., Ferrari, R., 2014. Rationalizing the spatial distribution of mesoscale eddy diffusivity in terms of mixing length theory. J. Phys. Oceanogr., 44. http://dx.doi.org/10.1175/JPO-D-13-0130.1.

Borghini, M., Bryden, H., Schroeder, K., Sparnocchia, S., Vetrano, A., 2014. The Mediterranean is becoming saltier. Ocean Sci. 10, 693-700. http://dx.doi.org/ 10.5194/os-10-693-2014.

Boutov, D., Peliz, A., Miranda, P.M., Soares, P.M., Cardoso, R.M., Prieto, L., Ruiz, J., García-Lafuente, J., 2014. Inter-annual variability and long term predictability of exchanges through the Strait of Gibraltar. Global Planet. Change 114, 23-37. http://dx.doi.org/10.1016/j.gloplacha.2013.12. 009.

Calafat, F.M., Chambers, D.P., Tsimplis, M.N., 2012. Mechanisms of decadal sea level variability in the Eastern North Atlantic and the Mediterranean Sea. J. Geophys. Res. 117, C09022. http://dx.doi.org/10.1029/2012JC008285.

Carracedo, L.I., Gilcoto, M., Mercier, H., Pérez, F.F., 2014. Seasonal dynamics in the Azores-Gibraltar Strait region: a climatologically-based study. Prog. Oceanogr. 122, 116-130. http://dx.doi.org/10.1016/j.pocean.2013.12.005.

Coelho, H.S., Neves, R.J.J., White, M., Leitao, P.C., Santos, A.J., 2002. A model for ocean circulation on the Iberian coast. J. Mar. Syst. 32, 153-179. 
Criado-Aldeanueva, F., Soto Navarro, F., García-Lafuente, J., 2014. Large-scale atmospheric forcing influencing the long-term variability of Mediterranean heat and freshwater budgets: climatic indices. J. Hydrometeorol. 15, 650-663. http://dx. doi.org/10.1175/JHM-D-13-04.1.

Cropper, T.E., Hanna, E., Bigg, G.R., 2014. Spatial and temporal seasonal trends in coastal upwelling off Northwest Africa, 1981-2012. Deep Sea Res. I 86, 94-111. http://dx.doi.org/10.1016/j.dsr.2014.01.007.

Echevarría, F., García-Lafuente, J., Bruno, M., Gorsky, G., Goutx, M., González, N., García, C.M., Gómez, F., Vargas, J.M., Picheral, M., Striby, L., Varela, M., Alonso, J.J., Reul, A., Cózar, A., Prieto, L., Sarhan, T., Plaza, F., Jiménez-Gómez, F., 2002. Physicalbiological coupling in the Strait of Gibraltar. Deep Sea Res. II 49 (19), 4115-4130.

Eden, C., Willebrand, J., 2000. Mechanisms of interannual to decadal variability of the North Atlantic circulation. J. Clim. 14, 2266-2280.

Frouin, R., Fuiza, A.F., Ambar, I., Boyd, T.J., 1990. Observations of a Poleward Surface Current off the coasts of Portugal and Spain during the winter. J. Geophys. Res. 95, 679-691.

García-Lafuente, J., Del Río, J., Alvarez-Fanjul, E., Gomis, D., Delgado, J., 2004. Some aspects of the seasonal sea level variations around Spain. J. Geophys. Res. 109, C09008. http://dx.doi.org/10.1029/2003JC002070.

García-Lafuente, J., Ruiz, J., 2007. The Gulf of Cádiz pelagic ecosystem: a review. Prog. Oceanogr. 74 (2-3), 228-251. http://dx.doi.org/10.1016/j.pocean.2007.04.001.

García-Lafuente, J., Sánchez-Garrido, J.C., Díaz del Rio, G., Criado-Aldeanueva, F., Marcote, D., Sánchez-Román, A., 2008. Low frequency variability of the Mediterranean undercurrent off Galicia, northwestern Iberian Peninsula. J. Mar. Syst. 74, 351-363. http://dx.doi.org/10.1016/j.jmarsys.2008.02.007.

Gómez-Enri, J., Aboitiz, A., Tejedor, B., Villares, P., 2012. Seasonal and interannual variability in the Gulf of Cadiz: validation of gridded altimeter products. Estuarine Coast. Shelf Sci. 96, 114-121. http://dx.doi.org/10.1016/j.ecss.2011.10.013.

Grignon, L., Smeed, D.A., Bryden, H.L., Schroeder, K., 2010. Importance of the variability of hydrographic preconditioning for deep convection in the Gulf of Lion, NW Mediterranean. Ocean Sci. 6, 573-586. http://dx.doi.org/10.5194/os-6 573-2010.

Haynes, R., Barton, E.D., 1990. A poleward flow along the Atlantic coast of the Iberian Peninsula. J. Geophys. Res. 95, 11425-11441.

Jia, Y., 2000. Formation of an Azores Current due to the Mediterranean overflow in a modeling study of the North Atlantic. J. Phys. Oceanogr. 30, 2342-2358.

Johnson, J., Stevens, I., 2000. A fine resolution model of the eastern North Atlantic between the Azores, the Canary Islands and the Gibraltar Strait. Deep Sea Res. I 47, 875-899.

Kalnay, E., Kanamitsu, M., Kistler, R., Collins, W., Deaven, D., Gandin, L., Iredell, M. Saha, S., White, G., Woollen, J., Zhu, Y., Leetmaa, A., Reynolds, R., Chelliah, M. Ebisuzaki, W., Higgins, W., Janowiak, J., Mo, K., Ropelewski, C.,, Wang, J., Jenne, R., Joseph, D., 1996. The NCEP/NCAR 40-year reanalysis project. Bull. Am Meteorol. Soc. 77, 437-470.

López-Jurado, J.L., González-Pola, C., Vélez-Belchi, P., 2005. Observations of an abrupt disruption of the long-term warming trend at the Balearic Sea, Western Mediterranean Sea, in summer 2005. Geophys. Res. Lett. 32, L24606. http://dx doi.org/10.1029/2005GL024430.

Machín, F., Pelegrí, J.L., Marrero-Díaz, A., Laiz, I., Ratsimandresy, A.W., 2006. Nearsurface circulation in the Southern Gulf of Cadiz. Deep Sea Res. II 53, 1161-1181. http://dx.doi.org/10.1016/j.dsr.2006.04.001.

Mariotti, A., Pan, Y., Zeng, N., Alessandri, A., 2015. Long-term climate change in the Mediterranean region in the midst of decadal variability. Clim. Dyn. , http://dx. doi.org/10.1007/s00382-015-2487-3.

Marshall, J., Hill, C., Perelman, L., Adcroft, A., 1997a. Hydrostatic, quasi-hydrostatic and non hydrostatic ocean modeling. J. Geophys. Res. 102 (C3), 5733-5752. http://dx.doi.org/10.1029/96JC02776.

Marshall, J., Adcroft, A., Hill, C., Perelman, L., Heisey, C., 1997b. A finite-volume incompressible Navier Stokes model for studies of the ocean on parallel computers. J. Geophys. Res. 102, 5753-5766. http://dx.doi.org/10.1029/ 96JC02775.
Martins, C.S., Hamann, M., Fuiza, A.F.G., 2002. Surface circulation in the eastern North Atlantic from drifters and altimetry. J. Geophys. Res. 107, 3217. http://dx. doi.org/10.1029/2000JC000345.

Marty, J.C., Chiavérini, J., 2010. Hydrologycal changes in the Ligurian Sea (NW Mediterranean, DYFAMED site) during 1995-2007 and biogeochemical consequences. Biogeosciences 7, 2117-2128. http://dx.doi.org/10.5194/bg-7-21172010.

Millot, C., 2007. Interannual salinification of the Mediterranean inflow. Geophys. Res. Lett. 34, L21609. http://dx.doi.org/10.1029/2007GL031179.

Millot, C., Candela, J., Fuda, J.L., Tber, Y., 2006. Large warming and salinification of the Mediterranean outflow due to changes in its composition. Deep Sea Res. I, 656-666. http://dx.doi.org/10.1016/j.dsr.2005.12.017.

Millot, C., García-Lafuente, J., 2011. About the seasonal and fortnightly variabilities of the Mediterranean outflow. Ocean Sci. 7, 421-428. http://dx.doi.org/10.5194/ os-7-421-2011.

Peliz, A., Marchesiello, P., Santos, A.M.P., Dubert, J., Teles-Machado, A., MartaAlmeida, M., Le Cann, B., 2009. Surface circulation in the Gulf of Cadiz: 2. Inflow-outflow coupling and the Gulf of Cadiz slope current. J. Geophys. Res. 114, C03011. http://dx.doi.org/10.1029/2008JC004771.

Pérez, F.F., Castro, C.G., Alvarez-Salgado, X.A., Rios, A.F., 2001. Coupling between the Iberian basin-scale circulation and the Portugal boundary current system: a chemical study. Deep Sea Res. I 48, 1519-1533.

Preisendorfer, R.W., 1988. Principal component analysis in meteorology and oceanography. Developments in Atmospheric Science, vol. 17. Elsevier, Amsterdam.

Roemmich, D., Gilson, J., 2009. The 2004-2008 mean and annual cycle of temperature, salinity, and steric height in the global ocean from the Argo Program. Prog. Oceanogr. 82, 81-100.

Rohling, E.J., Bryden, H.L., 1992. Man-induced salinity and temperature increases in Western Mediterranean deep water. J. Geophys. Res. 97 (C7), 11191-11198.

Sánchez-Leal, R., Relvas, P., Delgado, M., 2007. Coupled ocean wind and sea surface temperature patterns off the western Iberian Peninsula. J. Mar. Syst. 68, 103-127. http://dx.doi.org/10.1016/j.jmarsys.2006.11.003.

Sánchez-Garrido, J.C., Sannino, G., Liberti, L., García-Lafuente, J., Pratt, L., 2011. Numerical modelling of three-dimensional stratified tidal flow over Camarinal Sill, Strait of Gibraltar. J. Geophys. Res. 116, C12026. http://dx.doi.org/10.1029/ 2011JC007093.

Schroeder, K., Josey, S.A., Herrmann, M., Grignon, L., Gasparini, G.P., Bryden, H.L. 2010. Abrupt warming and salting of the Western Mediterranean Deep Water after 2005: atmospheric forcings and lateral advection. J. Geophys. Res. 115, C08029. http://dx.doi.org/10.1029/2009JC005749.

Skliris, N., Sofianos, S., Lascaratos, A., 2007. Hydrological changes in the Mediterranean Sea in relation to changes in the freshwater budget: a numerical modelling study. J. Mar. Syst. 65, 400-416. http://dx.doi.org/10.1016/j. jmarsys.2006.01.015.

Skliris, N., Marsh, R., Josey, S.A., Good, S.A., Liu, C., Allan, R.P., 2014. Salinity changes in the World Ocean since 1950 in relation to changing surface freshwater fluxes. Clim. Dyn. 43, 709-736. http://dx.doi.org/10.1007/s00382-014-2131-7.

Soto Navarro, J., Criado-Aldeanueva, F., Sánchez-Garrido, J.C., García-Lafuente, J., 2012. Recent thermohaline trends of the Atlantic waters inflowing to the Mediterranean Sea. Geophys. Res. Lett. 39, L01604. http://dx.doi.org/10.1029/ 2011 GL049907.

Stramma, L., 1984. Geostrophic transport in the warm water sphere of the eastern subtropical North Atlantic. J. Mar. Res. 42, 537-558.

Stramma, L., Siedler, G., 1988. Seasonal changes in the North Atlantic subtropical gyre. J. Geophys. Res. 93 (C7), 8111-8118.

Stramma, L., Isemer, H.J., 1988. Seasonal variability of the meridional temperature fluxes in the eastern North Atlantic Ocean. J. Mar. Res. 46, 281-299.

Wooster, W.S., Bakum, A., McLain, D.R., 1976. The seasonal upwelling cycle along the eastern boundary of the North Atlantic. J. Mar. Res. 34, 131-141. 